\title{
Divergencias de tasas de crecimiento entre las economías estatales de México, $1993-2010$
}

\author{
Juan Manuel Ocegueda Hernández*
}

Resumen: este documento analiza los determinantes de las diferencias en tasas de crecimiento entre las entidades federativas de México en el periodo 1993-2010, y propone una explicación que destaca el papel de tres factores: el fenómeno migratorio, que redistribuyó a la población económicamente activa en las regiones; las diferencias interestatales en las dotaciones de capital humano y en el comportamiento tanto de la inversión pública como de la extranjera directa, que influyeron en la capacidad de las regiones para generar empleos de buena calidad, y la terciarización del empleo, que se acompañó con un incremento en la participación relativa de las actividades de baja productividad, en particular las vinculadas al sector del hogar.

Palabras clave: análisis de economías regionales; crecimiento económico; tendencias demográficas; inversión pública; productividad sectorial.

Abstract: this article analyzes the determinants of differences in growth rates between Mexican states during 1993-2010,

* Universidad Autónoma de Baja California (UABC). Avenida Álvaro Obregón, s/n, C. P. 21100, colonia Nueva, Mexicali, Baja California, México. UABC, edificio Rectoría. Teléfono (686) 551 8280. Correo electrónico: jmocegueda@uabc.edu.mx 
and proposes an explanation that highlights the role of three factors: the migration phenomenon that reallocated the economically active population among regions; interstate differences in human capital endowments, as well as in the public and foreign investment behavior that influenced the ability of regions to generate high quality jobs; and employment growth in services, which was accompanied by an increase in the share of low productivity activities, especially those related to the household sector.

Key words: analysis of regional economies; economic growth; demographic trends; public investment; productivity of economic sectors.

\section{Introducción}

La tasa de crecimiento de la economía mexicana ha sido baja durante las últimas dos décadas: entre 1990 y 2012 creció 2.7 por ciento anual, si se considera el producto interno bruto (PIB) y 1.2, si se toma como referencia el PIB per cápita. Este pobre desempeño ocurre en un contexto de heterogeneidad regional, que ha favorecido una redistribución geográfica del ingreso nacional, al considerar las expectativas optimistas que generaron las reformas estructurales implementadas a partir de los años ochenta, con la firma del Tratado de Libre Comercio de América del Norte (TLCAN).

En la literatura reciente sobre estudios regionales, la explicación de estas diferencias se atribuye a factores como el proceso de especialización en la economía nacional y en los estados, que limitó la contribución del sector manufacturero al crecimiento económico (Sánchez 2011; Ocegueda et al. 2009). También se señalan las desigualdades en las dotaciones tecnológicas y en los ritmos de innovación en cada entidad (Mendoza et al. 2008), así como el papel del capital humano y la infraestructura productiva que permitieron a los estados con mejores dotaciones aprovechar las oportunidades que generó la apertura, sobre todo el TLCAN (Chiquiar 2005; Fuentes y Mendoza 2003). Si bien estas explicaciones son consistentes con 
la teoría económica y se corroboran en mayor o menor medida por la evidencia empírica, se deja de lado el cambio demográfico, fenómeno que al menos durante los últimos 20 años ha condicionado la trayectoria de la economía nacional y de sus regiones.

México redujo el ritmo de expansión demográfica desde 1980, de 3.3, en 1960-1980, pasó a 1.5 por ciento, en 1990-2010; en forma paralela, se registraron cambios en la estructura poblacional por grupos de edad cuyo impacto económico más significativo fue el rápido incremento de la población económicamente activa (PEA). Este hecho y el bajo dinamismo de la inversión que según Moreno Brid y Ros (2009) es la principal causa del lento crecimiento, tuvieron un efecto determinante en la distribución regional del ingreso, a través de los procesos migratorios que reubicaron la residencia de miles de familias. Una fracción elevada de la mano de obra emergente abandonó sus lugares de origen para dirigirse a Estados Unidos y a otros estados de la república, en busca de oportunidades laborales. Los efectos económicos ambivalentes asociados a la migración dependían de si la zona era receptora o expulsora; pues aumentaba (o reducía) las dotaciones de capital humano, y elevaba (o disminuía) la demanda por servicios públicos básicos y obras de urbanización, en detrimento de las finanzas de los gobiernos locales, lo que condicionaba el desempeño económico en el país.

El objetivo de este trabajo es aportar evidencia que contribuya a mejorar la comprensión sobre el proceso de divergencia regional, que muchos autores han documentado para el caso de México. El argumento central es que la interacción del fenómeno demográfico y la insuficiencia de la inversión para generar los puestos de trabajo, requeridos en las nuevas condiciones del mercado laboral, detonaron la expansión del sector informal y las actividades de baja productividad, lo que condujo a un modelo de especialización con un peso relativo alto de los segmentos productivos tradicionales. La caída de la productividad asociada con esta situación, la redistribución geográfica de la población, a través de la migración y las dotaciones desiguales de capital físico y humano, explican en gran medida el desempeño diferenciado entre las economías estatales.

El documento se divide en cuatro apartados, en el primero se revisan los principales argumentos teóricos para explicar las diferen- 
cias en tasas de crecimiento considerando algunas de las teorías más importantes en el debate actual; en el segundo se describen algunas cifras e indicadores que muestran el desempeño económico de las entidades en el periodo de estudio; asimismo, se ilustran las principales tendencias demográficas tanto nacionales como regionales, se comparan las dotaciones interestatales de capital físico y humano, y se analiza el proceso de especialización regional con énfasis en el rol del sector hogar, el cual aglutina a las actividades de menor productividad. En el tercero se presentan algunos ejercicios econométricos multivariantes que dan soporte a la hipótesis principal de este trabajo, y al final se incluyen algunas reflexiones a manera de conclusiones.

\section{Determinantes del crecimiento económico}

Acumulación de factores y aumento de la productividad

Una de las conclusiones del debate reciente en la teoría del crecimiento es que la acumulación de factores ya sea en forma de capital físico o humano, junto con la innovación tecnológica, son las fuerzas que dirigen el crecimiento económico. Sin embargo, los argumentos para llegar a esta conclusión y los canales, a través de los cuales interactúan las variables asociadas a estos procesos, difieren de acuerdo con la escuela del pensamiento de que se trate. Esta visión se aleja del viejo modelo neoclásico (vMN) desarrollado por Solow (1956), por lo menos en dos aspectos fundamentales: a) en el vMN la acumulación de factores sólo tiene efectos de largo plazo en el nivel de ingreso por habitante y b) en el vMN la innovación y el incremento asociado en la productividad total de los factores depende de eventos fortuitos en el ámbito de la ciencia y la tecnología, y no de inversiones sistemáticas e intencionadas orientadas a la generación de conocimientos. Esto supone una ausencia de vínculos entre la política económica y el crecimiento que deja una gran insatisfacción, pues implica que no se puede hacer nada para mejorar el desempeño económico de largo plazo (Ros 2004).

La idea de la importancia de la acumulación del capital físico se remonta por lo menos a los trabajos pioneros de Harrod (1939) y 
Domar (1946), en donde se asume una relación proporcional entre las tasas de inversión (inversión/PIB) y de crecimiento del PIB. El modelo resultante a partir de estos trabajos fue utilizado durante muchos años en ejercicios de planeación financiera, que desde el Banco Mundial intentaban determinar las necesidades de financiamiento de los países pobres, con la finalidad de alcanzar niveles de inversión compatibles con tasas de crecimiento deseadas. En un documento posterior, Kaldor (1957) formuló un modelo en donde la inversión en máquinas, que depende de forma positiva de la distribución del ingreso en favor de los beneficios, incrementa la productividad laboral al acelerar la incorporación de los avances tecnológicos y promover el aprendizaje por experiencia en las actividades productivas. En éste, la acumulación de capital físico y los aumentos en la productividad se retroalimentan mutuamente, lo que permite endogenizar la tasa de progreso técnico.

La relación entre inversión física y crecimiento está presente también en Lewis (1950), quien destaca el carácter dual de las economías subdesarrolladas, como un elemento central que define su trayectoria hacia el equilibrio de estado estacionario, a través de una ruta diferente a la que sugiere el vMN. En su opinión, el camino al desarrollo pasa por la industrialización, que se puede alentar promoviendo nuevas inversiones en el ramo manufacturero que aprovechen la abundante mano de obra que, por un periodo prolongado, puede proveer el sector tradicional. Por su parte, Rostow (1960) define cinco etapas del crecimiento en donde la primera corresponde al "despegue", cuyo principal ingrediente es un gran esfuerzo inicial de inversión. Rosenstein Rodan (1943), mediante un razonamiento parecido basado en su teoría del "gran empujón”, sostiene que el estancamiento de los países pobres puede superarse a través de un programa coordinado de grandes inversiones públicas y privadas, que permitan aprovechar de una forma favorable los rendimientos crecientes de las actividades modernas y la gran disponibilidad de trabajo que caracteriza a estas economías.

Lucas (1988) fue el primero en establecer la relación entre acumulación de capital humano y crecimiento económico. La idea principal en este trabajo es que la reproducción del capital físico (K) es comandada por la disponibilidad de capital humano $(\mathrm{H})$, el que a 
su vez puede producirse sin límites y en proporción directa a los recursos que la sociedad y los individuos destinan para este fin. Si se supone que la inversión en $\mathrm{H}$ es una fracción fija del PIB, y que su producción se realiza sólo con $\mathrm{H}$, mientras que la de bienes se lleva a cabo con $\mathrm{K}$ y $\mathrm{H}$, ambas funciones en condiciones de rendimientos constantes a escala, se puede demostrar que el proceso de acumulación se sostiene indefinidamente sin necesidad de progreso técnico exógeno. Romer (1986) propone una versión alternativa basada en la acumulación de conocimientos, que se difunden a través de externalidades, mientras que en Romer (1990) es mediante la inversión social en investigación científica y desarrollo tecnológico. La idea central es que la producción de conocimientos es especial, en donde los rendimientos sociales superan a los privados, lo que garantiza altas tasas de rentabilidad que sostienen el proceso de acumulación de capital en el tiempo.

El enfoque Lucas-Romer fue muy influyente en los años noventa y principios del siglo XxI, y dio lugar a la corriente llamada nueva teoría del crecimiento (NTC) que, cuando se alejó del VMN, estableció una conexión de causalidad entre política económica y crecimiento. Para esta escuela, invertir no es suficiente para crecer, es necesario además que se realice de manera eficiente, lo cual requiere la adopción de políticas de libre mercado, la reducción del tamaño del gobierno y el mantenimiento de los precios relativos correctos o de equilibrio (Obregón 2008). Asimismo, se destaca la importancia de la especialización en áreas productivas con altas tasas de aprendizaje y externalidades tecnológicas, y en donde el progreso técnico es endógeno, y se sostiene que los países orientados a fabricar bienes de alto contenido tecnológico pueden crecer más rápido, que los que producen los tradicionales, debido a que sus oportunidades de innovación son mayores (Romer 1990; Grossman y Helpman 1991).

La especialización es una vía que vincula la acumulación de factores con la innovación técnica que no es exclusiva de la NTC, en realidad casi todos los autores mencionados sostienen que la industrialización promueve el crecimiento. Según la literatura poskeynesiana, la especialización en actividades con rendimientos crecientes a escala acelera el incremento de la productividad en el conjunto de la economía, como resultado del progreso técnico inducido o debido 
a la absorción de recursos provenientes de ramos menos productivos (Kaldor 1970; 1966). Asimismo, puede tener efectos favorables, cuando se orienta a la producción de bienes con altas elasticidades ingreso, debido a que eleva la competitividad en el comercio internacional, y permite la apropiación de una fracción creciente de la demanda externa a medida que ésta se expande (Thirlwall 1979; Thirlwall y Dixon 1979).

En los años noventa, lo que favoreció el desarrollo de la nueva escuela institucionalista fueron las dificultades para conciliar la teoría con una evidencia empírica internacional compleja y heterogénea, así como la obtención de resultados diferentes ante la aplicación de políticas económicas similares. Según esta escuela, el dinamismo de la inversión, la producción de capital humano y conocimientos, la capacidad para innovar y la eficacia misma de las políticas implementadas depende del entramado institucional, que soporta las transacciones económicas (Rodrik 2008). Ciertos arreglos institucionales propician más que otros la inversión productiva y la innovación, sobre todo aquéllos que fomentan la educación, combaten la desigualdad y la pobreza, y proporcionan un marco jurídico que protege los derechos de propiedad sobre los bienes y las ideas, así como un aparato de justicia que garantiza la seguridad pública (North 1990).

La literatura referida se puede sintetizar en cuatro ideas principales, en torno a las fuerzas que impulsan el progreso técnico: a) la acumulación de capital, a través de la sustitución de máquinas y equipo obsoleto, que permite incorporar los avances científico-tecnológicos; b) las mejoras en la organización de los procesos productivos, como consecuencia de los aumentos en la escala de la producción o vía procesos de aprendizaje, que elevan la productividad laboral para un mismo acervo de capital, a medida que aumentan la producción y la experiencia; c) la inversión de recursos que la sociedad realiza para formar capital humano y generar conocimientos, así como las políticas empleadas para incentivar la innovación y d) el tipo de actividades productivas que se desarrollan y que ofrecen oportunidades diferenciadas para el aprendizaje, la innovación técnica y el acceso a mercados en expansión. Todas estas fuerzas son empujadas o inhibidas por el entramado institucional que subyace en cada país o región (Ocegueda 2000). 
Demografía, migración y crecimiento

La literatura sobre crecimiento económico ha destacado la importancia de los factores demográficos, aunque de una teoría a otra difieren sus efectos y las vías a través de las cuales repercuten en el desempeño de las economías. En el vMN, la expansión poblacional contrae el ingreso per cápita en el equilibrio de largo plazo, pero no la tasa a la que éste crece, la cual es determinada por el progreso técnico exógeno. En contraposición, la NTC establece un vínculo positivo entre tamaño y aumento de la población con respecto a la tasa de crecimiento del PIB per cápita, lo cual se asocia con efectos de escala que derivan de externalidades asociadas al capital agregado de la economía (Romer 1986), o por la introducción de una función de producción de conocimientos en la que el factor trabajo corresponde a una fracción constante de la población (Romer 1990). Si bien este resultado es polémico y difícil de conciliar con la experiencia internacional, para explicar diferencias en tasas de crecimiento entre países, Kremer (1993) demuestra que cuando esta idea se aplica al mundo como una sola economía y en periodos muy largos, por ejemplo varios siglos, dicho resultado se vuelve consistente con la evidencia empírica, y hay una fuerte correlación estadística entre el tamaño de la población y el PIB per cápita, así como entre sus respectivas tasas de crecimiento.

Un mayor dinamismo demográfico puede incidir de manera negativa en el crecimiento, si éste es impulsado por la tasa de ahorro, toda vez que un mayor tamaño poblacional aumenta el consumo agregado y su participación dentro del PIB, así como la dependencia en las familias y en la sociedad (población total/población ocupada), lo que a su vez inhibe el incremento del ingreso per cápita. Asimismo, su efecto sobre los flujos migratorios puede alterar la trayectoria de largo plazo de la economía, aunque no está claro el sentido en que ésta se modifica y depende de la composición de la población migrante y de las condiciones económicas generales de las zonas expulsoras y receptoras. Ahora bien, el fenómeno migratorio, en la medida que conlleva a una redistribución espacial de personas y familias, incide en el comportamiento demográfico en las áreas geográficas donde ocurre, y se establece una relación endógena entre aumento 
poblacional y migración, cuando se analiza desde una perspectiva regional.

La relación entre migración y crecimiento es compleja y bidireccional: una región exitosa que ofrece empleos bien remunerados atrae a personas de otras latitudes, que no encuentran las mismas oportunidades en sus lugares de origen; a su vez, la disponibilidad de mano de obra abundante atrae nuevas inversiones, que fortalecen la situación económica inicial. Lo contrario ocurre en la zona geográfica expulsora, casi siempre más pobre, en donde la pérdida de mano de obra joven y la frecuente condición que las caracteriza, de contar con una mayor expansión demográfica, modifica desfavorablemente la tasa de dependencia acentuando las condiciones iniciales de pobreza (Myrdal 1957). Esta secuencia de hechos describe una dinámica acumulativa circular, destacada por autores como Kaldor (1970; 1966), cuando formula las tres leyes que llevan su nombre, en donde sostiene que el acceso a una oferta laboral abundante en las regiones económicamente más dinámicas, parte de la cual puede proveer la migración, permite aprovechar las ventajas asociadas con la expansión de sectores y actividades que operan con rendimientos crecientes, lo cual contribuye a elevar la tasa de crecimiento del producto por periodos prolongados.

En los planteamientos anteriores subyace la idea de que la migración favorece el desempeño económico de las zonas receptoras y perjudica a las expulsoras, y que una de las razones principales de ello es la trasferencia de capital humano entre unas y otras. Sin embargo, existen circunstancias en las que este mecanismo puede fallar ocasionando un resultado diferente, en particular cuando la inversión no aumenta en proporción a los influjos de mano de obra en las áreas que reciben migrantes, en cuyo caso crecen el subempleo y el desempleo, al mismo tiempo que proliferan las actividades informales de baja productividad (Harris y Todaro 1970). También se pueden tener efectos en sentido inverso, cuando los costos económicos y sociales en las áreas receptoras son demasiado altos, ya sea porque se destinan muchos recursos públicos para atender necesidades relacionadas con obras urbanas y provisión de servicios básicos en nuevos asentamientos humanos, o porque el aumento de personas desempleadas o subempleadas estimula la delincuencia y un 
ambiente de inseguridad que inhibe la acumulación de capital. Las zonas expulsoras se benefician por las razones contrarias, al liberarse de presiones sociales, laborales y sobre el gasto público. Se puede agregar que la migración repercute en el crecimiento económico de manera indirecta, a través de sus efectos en la dinámica demográfica.

\section{Desempeño reciente de la economía mexicana}

La economía de México ha tenido un desempeño pobre en las últimas dos décadas, situación que aleja cada vez más al país de la trayectoria que podría convertirlo en uno desarrollado. Entre 1990 y 2010 el producto por habitante pasó apenas de 27.8 a 28.3 por ciento, con respecto al de Estados Unidos. Esto es preocupante, si se considera que en 1981 representaba 39.3, y que en el mismo periodo Chile pasó de 17.8 a 29.2; Corea del Sur, de 36.2 a 60.9, y China, de 4.0 a 17.1 (Penn World Tables 7.1, 2012).

En el ámbito regional, el lento crecimiento ha acentuado las desigualdades de ingreso entre las economías que se encuentran en los extremos de la distribución, las oportunidades de progreso social se han concentrado en algunas zonas geográficas privilegiadas con mayores capacidades competitivas, infraestructura física y dotaciones de capital humano, en detrimento de otras que no cuentan con las mismas condiciones. Sin embargo, este proceso no ha sido homogéneo entre regiones, ni entre estados de una misma área, y se ha observado la interacción de procesos convergentes y divergentes. En la figura 1 aparece la relación entre la tasa de crecimiento del PIB per cápita 1993-2010 de las 32 entidades con el nivel de desarrollo alcanzado por cada una en 1993, el cual se mide con la brecha de ingreso con respecto al Distrito Federal, que tenía el mayor. Se trata de una representación que permite identificar los patrones de convergencia y divergencia regional, ${ }^{1}$ y en la que se puede observar a un grupo

\footnotetext{
${ }^{1}$ Un patrón de convergencia se puede identificar cuando un grupo de entidades se sitúa entre sí en torno a una línea con pendiente negativa, lo cual implica que las de menor ingreso (de ese grupo) en el año inicial (1993) tuvieron un crecimiento mayor en el periodo posterior (1993-2010). Asimismo, un patrón de divergencia se tiene cuando los estados se ubican en torno a una línea con pendiente positiva, lo cual sugiere lo contrario, es decir, que los que
} 


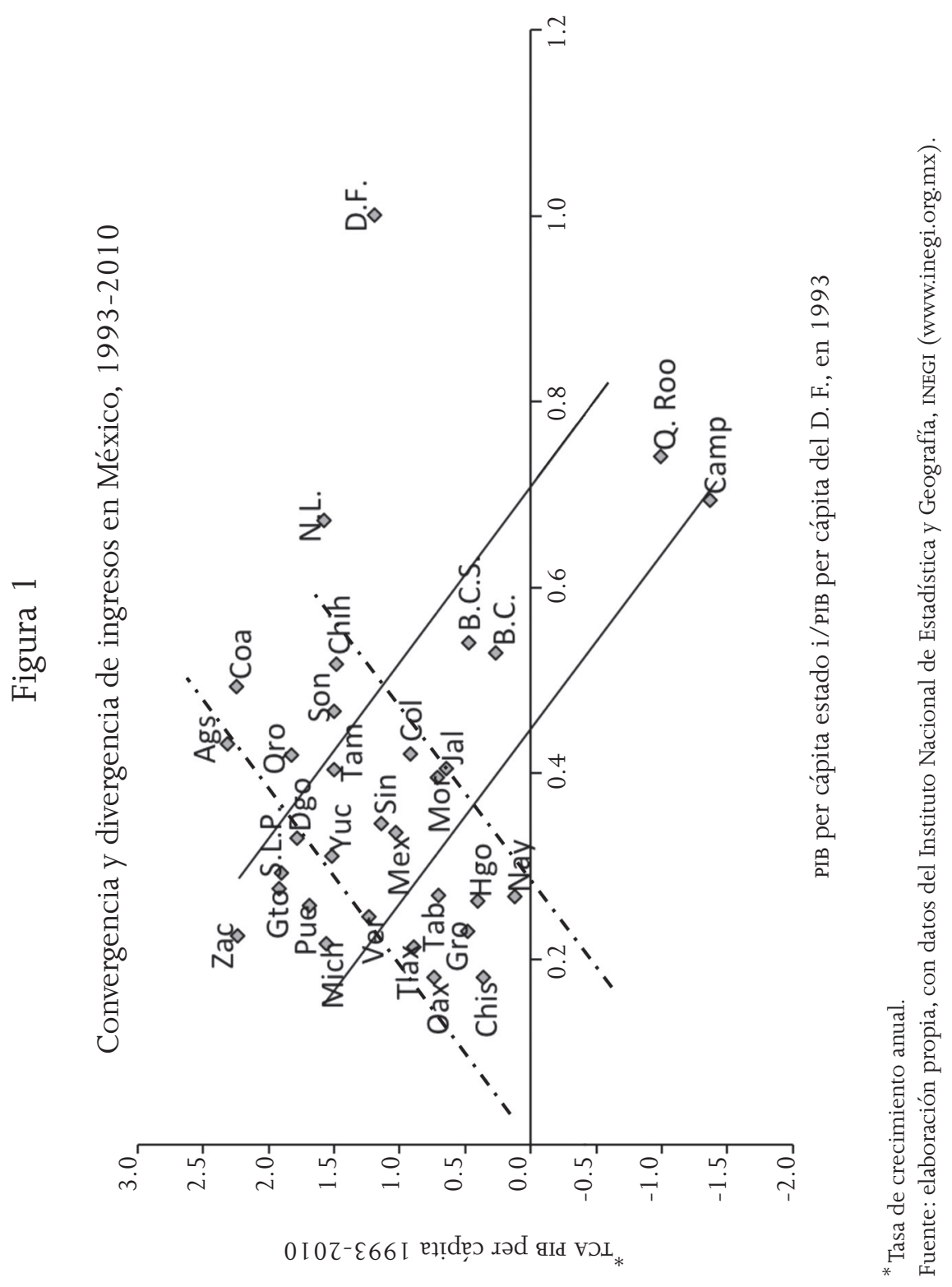


de 18 estados, situados entre las dos líneas paralelas continuas, en donde la brecha de ingresos disminuye (convergencia). Asimismo, hay un segundo grupo de 16 entre las líneas punteadas, en los que se acrecentaron $^{2}$ (divergencia) las distancias en los ingresos.

Si se descompone el PIB per cápita ( $\mathrm{PIB} / \mathrm{POB})$, tal que $\mathrm{PIB} / \mathrm{POB}=$ (PIB/PO), en donde PIB/PO es el PIB por persona ocupada y PO/POB es la tasa de actividad económica, ${ }^{3}$ y luego se expresa en tasas de crecimiento se tiene: TCA_PIB/РOB $=$ TCA_ PIB/PO + TCA_ PO/POB. Si se aplica este ejercicio a las entidades, se aprecia que la principal fuente de crecimiento está en la tasa de actividad económica y no en la productividad del trabajo, como correspondería a una economía que se encuentra en una trayectoria de desarrollo, y en donde la generación de riqueza se acompaña con una distribución más equitativa de ella. La figura 2 ilustra esta situación, en ella se ordenan los 32 estados de acuerdo con las cifras de sus TCA_ PIB/POB. El componente TCA_ $\mathrm{PIB} / \mathrm{PO}$ es representado por el segmento claro mientras que el oscuro se refiere a la TCA_ PO/РОВ. Es fácil percibir que este último componente, el cual registra siempre valores positivos, tiene el mayor efecto sobre TCA_PIB/POB, porque la TCA_PIB/PO presenta valores negativos en más de la mitad de los estados. Esto significa que en la mayoría de ellos decreció el producto por trabajador, lo que sugiere un empeoramiento de las condiciones básicas para un crecimiento sostenido.

El predominio del efecto tasa de actividad en un contexto de estancamiento de la productividad o, en el mejor de los casos, de mejoras moderadas, supone un crecimiento basado en la expansión del empleo con alta participación de los sectores tradicionales, lo que limita la difusión de los beneficios sociales asociados con una menor tasa de dependencia económica.

Otro aspecto ilustrado por la figura 2 es que, con la excepción de Yucatán y Tabasco, las entidades con menor TCA_ PIB/POB coinciden con las que tienen una TCA_PIB/PO negativa. También se observa que

\footnotetext{
tienen menos ingresos (de ese grupo) en 1993 tuvieron un crecimiento menor, y los que tenían mayores percepciones crecieron más.

${ }^{2}$ Estas agrupaciones son arbitrarias y su carácter sólo es ilustrativo. Un subgrupo de estados puede estar en los dos grupos, pero compararse contra subgrupos distintos.

${ }^{3}$ El inverso de la tasa de actividad económica РОв/РO puede interpretarse como la tasa de dependencia económica.
} 


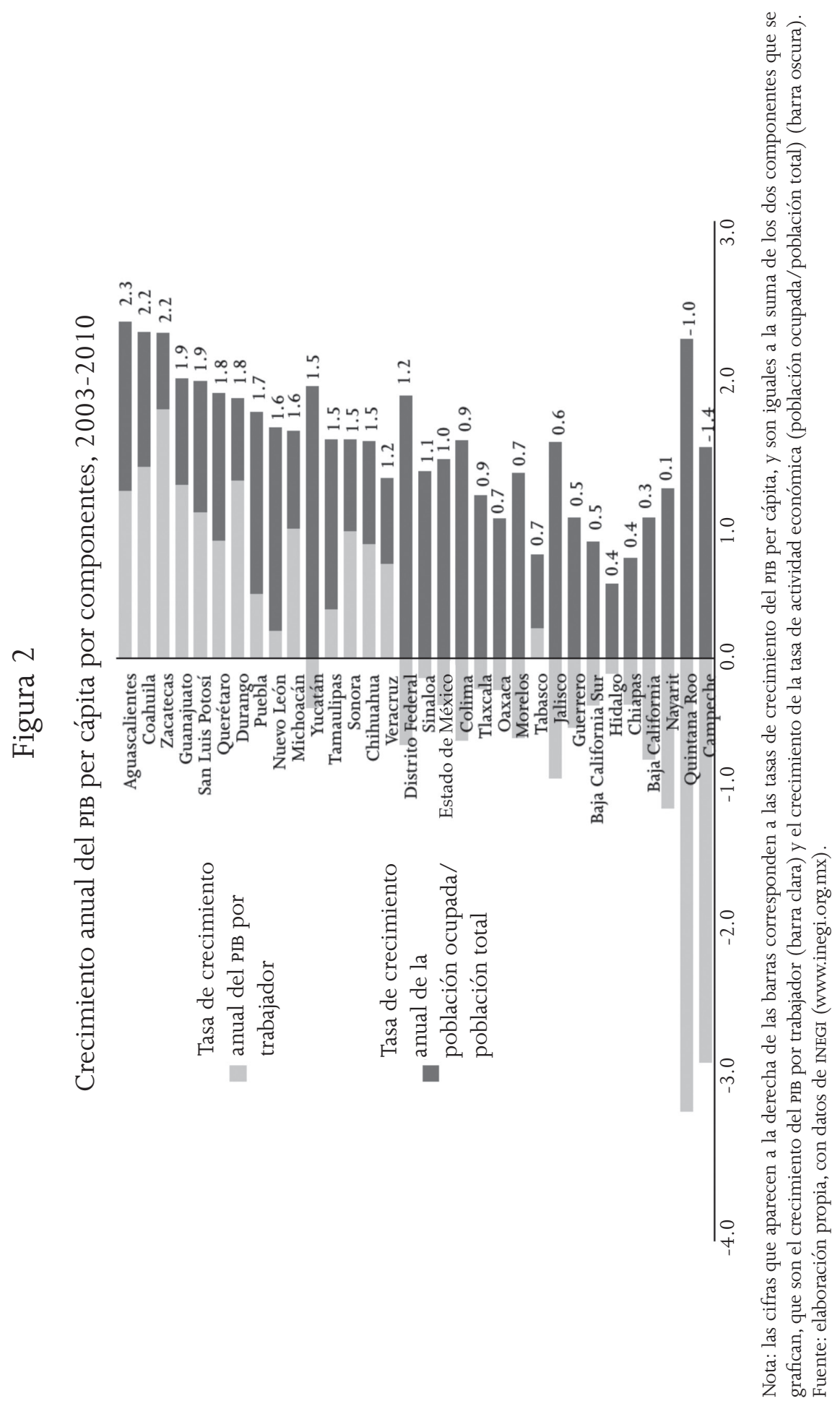


algunas crecen combinando valores positivos de las TCA_ PIB/PO y TCA_PO/POB; otras basan su crecimiento exclusivamente en el comportamiento de la TCA_PO/POB, y un grupo más decrece aun cuando la TCA_ PO/РOB alcanza valores positivos y altos. Esta diversidad de patrones sugiere un panorama regional complejo, cuya explicación debe considerar por lo menos cuatro fenómenos: a) los cambios demográficos, que modificaron las condiciones del mercado laboral, al incrementar la disponibilidad de mano de obra; b) la acumulación de capital físico, que se vio influida por la desaceleración en la inversión pública; c) la formación de capital humano, que fue favorecida por los logros importantes obtenidos en los ámbitos educativo y de la salud y d) los procesos de especialización, que condujeron al fortalecimiento de los sectores de baja productividad nacional.

\section{Cambios demográficos}

A partir de la década de 1990 se conjugan en México dos fenómenos demográficos, que modifican las condiciones para el crecimiento económico en el mediano plazo: por un lado, un cambio en la composición de la población por grupos de edad, que aumenta significativamente la PEA elevando las presiones sobre el mercado laboral; por otro, el país transita hacia un menor incremento demográfico ${ }^{4}$ que, aunado al evento anterior, permite reducir las tasas de dependencia económica de la población (véase figura 3). Esta conjunción plantea retos y oportunidades que no se han aprovechado para intensificar el dinamismo de la economía. Un aumento de la PEA en un contexto de desaceleración demográfica implica que una proporción mayor de la población se integra al mercado laboral, lo que por sí mismo debiera dinamizar la producción. La tasa de crecimiento del PIB per cápita se acelerará sólo si los nuevos miembros de la PEA se emplean en actividades de mediana y alta productividad, de lo contrario, la repercusión será positiva sobre el PIB pero mínima o nula sobre el producto por trabajador, lo cual mantendrá estancados los salarios reales y reducirá los niveles de bienestar.

${ }^{4}$ De 1960 a 1980 la tasa anual de crecimiento de la población fue de 3.3 por ciento; de 1980 a 1990 , de 2; de 1990 al año 2000 , de 1.6 y del año 2000 a 2010 , de 1.3. 


\section{Figura 3}

Evolución de la PEA en México 1940-2010 (\% de la población)

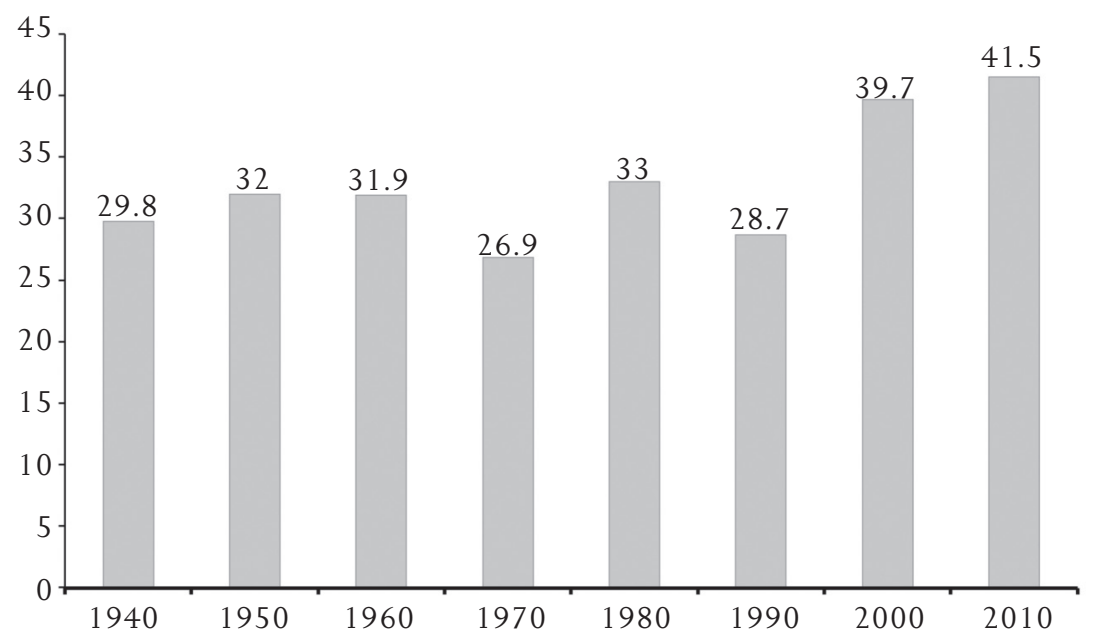

Fuente: elaboración propia, con datos del INEGI (www.inegi.org.mx), y del Consejo Nacional de Población, CONAPO (www.conapo.gob.mx).

La tendencia señalada se reprodujo de manera heterogénea en las entidades. Entre 1993 y 2010, la PEA creció 2.5 por ciento anual a escala nacional; 1.1 puntos por encima de la tasa a la que aumentó la población; no obstante, la distribución de ese crecimiento fue desigual. Gran parte de esa expansión se concentró en Quintana Roo, que tuvo una tasa anual de 6.9; Baja California Sur, de 4.4; Baja California, de 4.2; Querétaro, de 3.6; Colima, de 3.6; Aguascalientes, de 3.5 y Yucatán, de 3.5 por ciento. En el extremo contrario se ubicaron el Distrito Federal, Guerrero y Oaxaca, con 1.9; Durango, Michoacán y Veracruz, con 1.4 y Zacatecas, con 1.3 por ciento (véase figura 4). Los estados que lograron emparejar el ritmo de expansión de la inversión con el de la PEA debieron beneficiarse con la mayor disposición de fuerza laboral, no así aquéllos en donde la formación de capital permaneció estancada o sufrió contracciones.

Las tasas de crecimiento del PIB per cápita muestran que dentro del primer grupo sólo Aguascalientes, Querétaro y Yucatán tuvieron 


\section{Figura 4}

Tasas de crecimiento de indicadores económicos seleccionados,

1993-2010

\begin{tabular}{|l|c|c|c|c|c|}
\hline & PIB per cápita & PIB & Población & PEA & Tasa de migración neta \\
\hline Aguascalientes & 2.3 & 4.6 & 2.2 & 3.5 & 0.1 \\
\hline Baja California & 0.3 & 3.3 & 3.1 & 4.2 & 1.2 \\
\hline Baja California Sur & 0.5 & 4.0 & 3.5 & 4.4 & 1.1 \\
\hline Campeche & -1.4 & 0.4 & 1.8 & 3.3 & 0.0 \\
\hline Coahuila & 2.2 & 3.8 & 1.6 & 2.5 & -0.5 \\
\hline Colima & 0.9 & 2.9 & 2.0 & 3.6 & -0.1 \\
\hline Chiapas & 0.4 & 2.2 & 1.8 & 2.5 & -0.6 \\
\hline Chihuahua & 1.5 & 2.9 & 1.4 & 2.2 & -0.4 \\
\hline Distrito Federal & 1.2 & 1.5 & 0.3 & 1.9 & -1.0 \\
\hline Durango & 1.8 & 2.7 & 0.9 & 1.4 & -1.3 \\
\hline Guanajuato & 1.9 & 3.3 & 1.4 & 2.2 & -1.0 \\
\hline Guerrero & 0.5 & 1.4 & 0.9 & 1.9 & -1.4 \\
\hline Hidalgo & 0.4 & 1.9 & 1.5 & 2.0 & -0.7 \\
\hline Jalisco & 0.6 & 2.1 & 1.4 & 2.9 & -0.5 \\
\hline Estado de México & 1.0 & 2.9 & 1.9 & 3.2 & 0.1 \\
\hline Michoacán & 1.6 & 2.3 & 0.7 & 1.4 & -1.5 \\
\hline Morelos & 0.7 & 2.3 & 1.6 & 2.8 & -0.1 \\
\hline Nayarit & 0.1 & 1.4 & 1.2 & 2.4 & -1.0 \\
\hline Nuevo León & 1.6 & 3.5 & 1.9 & 3.2 & 0.0 \\
\hline Oaxaca & 0.7 & 1.6 & 0.8 & 1.9 & -1.1 \\
\hline Puebla & 1.7 & 3.2 & 1.5 & 2.8 & -0.5 \\
\hline Querétaro & 1.8 & 4.4 & 2.5 & 3.6 & 0.5 \\
\hline Quintana Roo & -1.0 & 3.5 & 4.6 & 6.9 & 2.7 \\
\hline San Luis Potosí & 1.9 & 3.0 & 1.1 & 2.1 & -0.9 \\
\hline Sinaloa & 1.1 & 2.0 & 0.8 & 2.1 & -1.0 \\
\hline Sonora & 1.5 & 3.2 & 1.7 & 2.4 & -0.3 \\
\hline Tabasco & 0.7 & 2.3 & 1.6 & 2.4 & -0.5 \\
\hline Tamaulipas & 1.5 & 3.2 & 1.7 & 2.9 & -0.1 \\
\hline Tlaxcala & 0.9 & 2.8 & 1.9 & 3.1 & 0.0 \\
\hline Veracruz & 1.2 & 2.1 & 0.8 & 1.4 & -1.0 \\
\hline Yucatán & 3.1 & 1.6 & 3.5 & 0.0 \\
\hline Zacatecas & 2.9 & 0.6 & 1.3 & -1.6 \\
\hline Nacional & 1.5 & 2.5 & 0.1 \\
\hline & 2.2 & & \\
\hline & 1.5 & & \\
\hline
\end{tabular}

Fuente: elaboración propia, con datos del INEGI (www.inegi.org.mx), y del CONAPO (www. conapo.gob.mx). 
un desempeño superior al promedio, mientras que en el segundo fueron el Distrito Federal, Durango, Michoacán, Veracruz y Zacatecas, lo cual sugiere una relación negativa entre los movimientos de la PEA y los del PIB per cápita. Este vínculo podría explicarse por la falta de inversión para absorber, en empleos productivos, a la mano de obra adicional que se incorporó al mercado laboral, lo que habría conducido a que ésta se ocupara en actividades informales de subsistencia y baja productividad. Es probable también que los aumentos en la PEA se hayan acompañado con incrementos en la población, que redujeron el producto por habitante, sobre todo si la PEA se expandió como resultado de la migración, y en este proceso los migrantes movilizaron a sus familias dando lugar a una expansión de la población, proporcionalmente mayor a la que ocurrió en la oferta de mano de obra. Lo que queda claro es que los estados expulsores trasfirieron las presiones laborales hacia los receptores.

Es importante considerar que el efecto negativo del aumento demográfico en el crecimiento económico puede compensarse si la composición de la población por grupos de edad se modifica de manera favorable para elevar la tasa de actividad de la economía, pues ello aumenta el porcentaje de personas que trabajan. No obstante, el efecto será desfavorable si los empleos se abren en sectores de baja productividad, o si los nuevos miembros de la PEA pasan a engrosar las filas de la subocupación y la desocupación. Un agravante adicional es la caída de los salarios reales, que deriva del exceso de mano de obra disponible. Por ello, es relevante analizar en qué sectores y tipos de actividad se ocuparon los nuevos miembros de la PEA, que irrumpieron en el mercado de trabajo en el periodo de estudio, aspecto que se aborda en el apartado sobre especialización.

Las cifras disponibles ilustran el papel crucial del fenómeno migratorio, como determinante del desempeño económico estatal. Baja California Sur, Baja California y Quintana Roo tuvieron la mayor recepción de migrantes, en relación con el tamaño de su población, con tasas de migración neta de $1.1,1.2$ y 2.7 por ciento respectivamente, y se ubican en las posiciones 25, 29 y 31 si se toma como referencia la tasa de crecimiento del PIB per cápita. Son también las entidades con mayor dinamismo demográfico, y donde más aumenta la PEA. Esta situación resulta paradójica, pues su pobre desempeño 
económico contrasta con la percepción de la gente que inmigra porque las concibe como tierras de oportunidades en donde es posible lograr un progreso económico.

El vínculo entre lento crecimiento y migración podría explicarse por los desequilibrios que genera este fenómeno, no sólo por su contribución al aumento poblacional, sino porque eleva exponencialmente la demanda de servicios públicos y deteriora la calidad de éstos, ejerce una presión desfavorable sobre el mercado laboral provocando la caída de los salarios y la proliferación de las labores de subsistencia, y eleva los niveles de pobreza en las áreas receptoras, toda vez que la composición social de los flujos migratorios suele estar alimentada por grupos provenientes de los estratos socioeconómicos más bajos.

\section{Diferencias en la formación de capital físico y humano}

Una de las hipótesis que explica el bajo crecimiento de la economía mexicana en las últimas dos décadas propone, como factor más importante, la caída de la inversión como proporción del PIB que resultó de la fuerte contracción del gasto gubernamental, en especial el destinado a ampliar y reponer infraestructura. De 1979 a 1981, la tasa de inversión fue de 24.9 por ciento; 13.9 de origen privado y 11 de público, mientras que de 2008 a 2010, la cifra fue de 22.2, 16.4 y 5.8 por ciento, respectivamente (Moreno Brid y Ros 2009). A la caída inicial, en los años ochenta, le siguió una recuperación lenta en ambos segmentos institucionales, pero con tendencias más favorables en el gubernamental, por lo menos en el periodo revisado aquí. Así, entre 1993 y 2010, la inversión total creció a 3.6 por ciento anual en promedio, la privada lo hizo a 3 y la pública a 5.6. A pesar de ello, la subinversión estatal que se ha tenido durante décadas podría haber generado secuelas de largo plazo difíciles de superar, aunque se recuperan las tasas de inversión previas, debido a los rezagos en la creación de infraestructura física y a sus efectos sobre las expectativas de la inversión privada.

La figura 5 muestra el comportamiento del PIB y de la formación bruta de capital fijo (FBKF), ponderados por el tamaño de la pobla- 


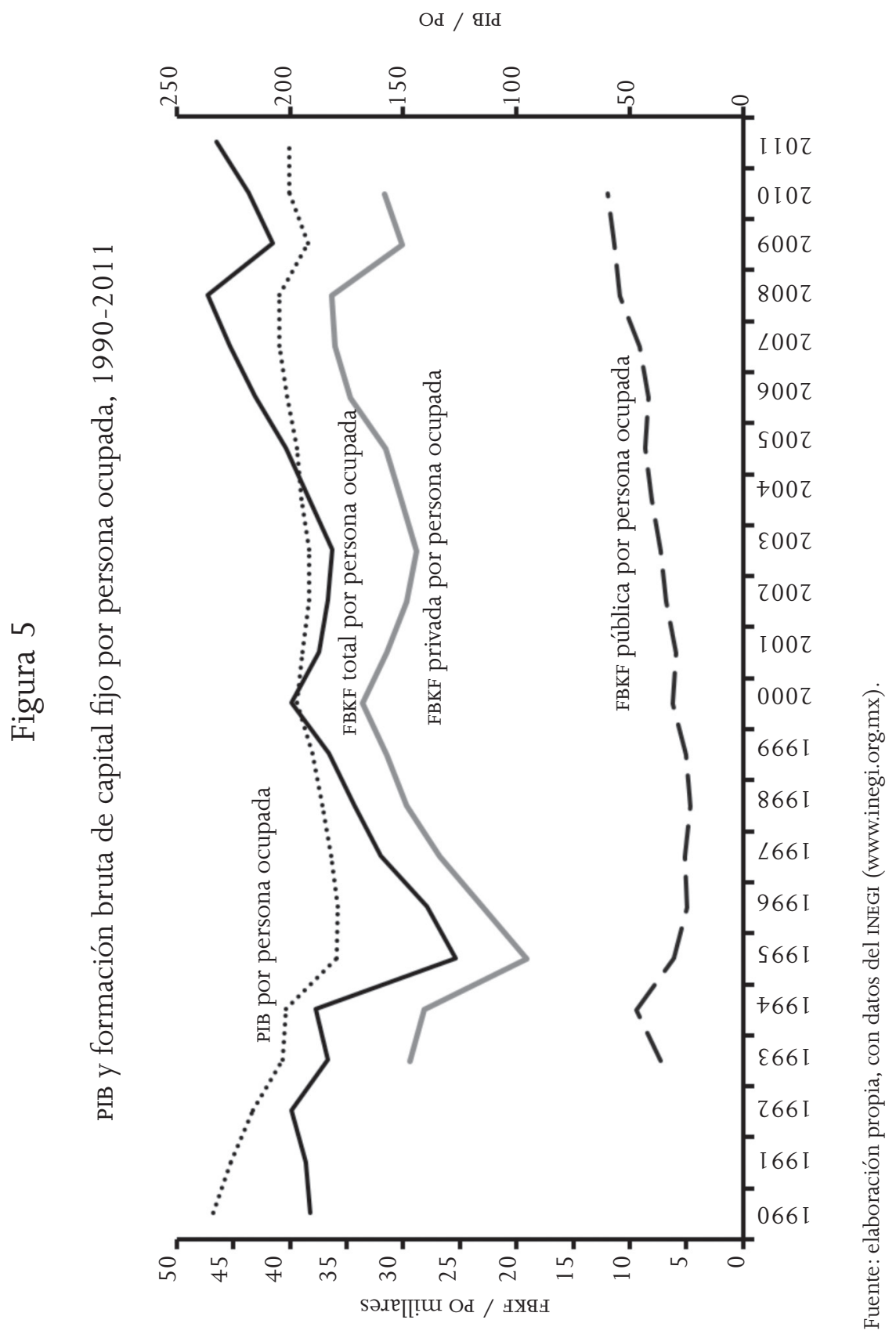


ción ocupada y en este último caso considerando sus componentes público y privado. Se aprecia que el estancamiento en el producto por trabajador se asocia con el aumento reducido de la inversión; que su componente público es una fracción significativamente menor que el privado; y que éste explica en lo fundamental las fluctuaciones en esa variable. Se observa también que la inversión por trabajador es más dinámica en el sector público que en el privado; el primero crece a una tasa de 3 por ciento anual, y el segundo a una de 0.4.

Evaluar la relación entre inversión y crecimiento por entidad plantea problemas difíciles de salvar, debido a que la primera de estas variables no se construye en las cuentas nacionales con este nivel de desagregación. No obstante, es posible lograr una aproximación con la inversión pública sumando la del gobierno federal, en infraestructura, con la de los estados en obras públicas, las cuales se pueden consultar en los informes de la Presidencia de la república y en el INEGI respectivamente. Al ponderar esta variable entre el personal ocupado y calcular tasas de crecimiento, se percibe que existen diferencias considerables entre las entidades, que bien podrían explicar la diversidad de desempeños económicos. Las cifras disponibles indican que Campeche, Tamaulipas, Yucatán y Zacatecas son las que más se benefician con los esfuerzos gubernamentales para ampliar infraestructura, seguidas por Durango, Chiapas, Coahuila y Tabasco, mientras que el Distrito Federal, Nayarit y Aguascalientes son las que menos beneficios reciben por esta vía (véase figura 6). Esto sugiere un escenario complejo, pues no todas las del primer y segundo grupos son de crecimiento rápido, ni las del último se corresponden con las de menor dinamismo económico, lo que podría ser evidencia del carácter multifactorial de la desaceleración económica del país. Sin embargo, es importante aclarar que este ejercicio no considera los montos invertidos por el sector privado, cuya inclusión al final podría modificar esta percepción.

La teoría económica enseña que en el desarrollo económico influye no sólo la inversión en capital físico e infraestructura, sino también la formación de capital humano, la cual suele medirse a través de la escolaridad promedio de la población trabajadora o por el porcentaje de empleados con determinados estudios, a menudo con educación secundaria (Mankiw et al. 1992). El primer indicador se 


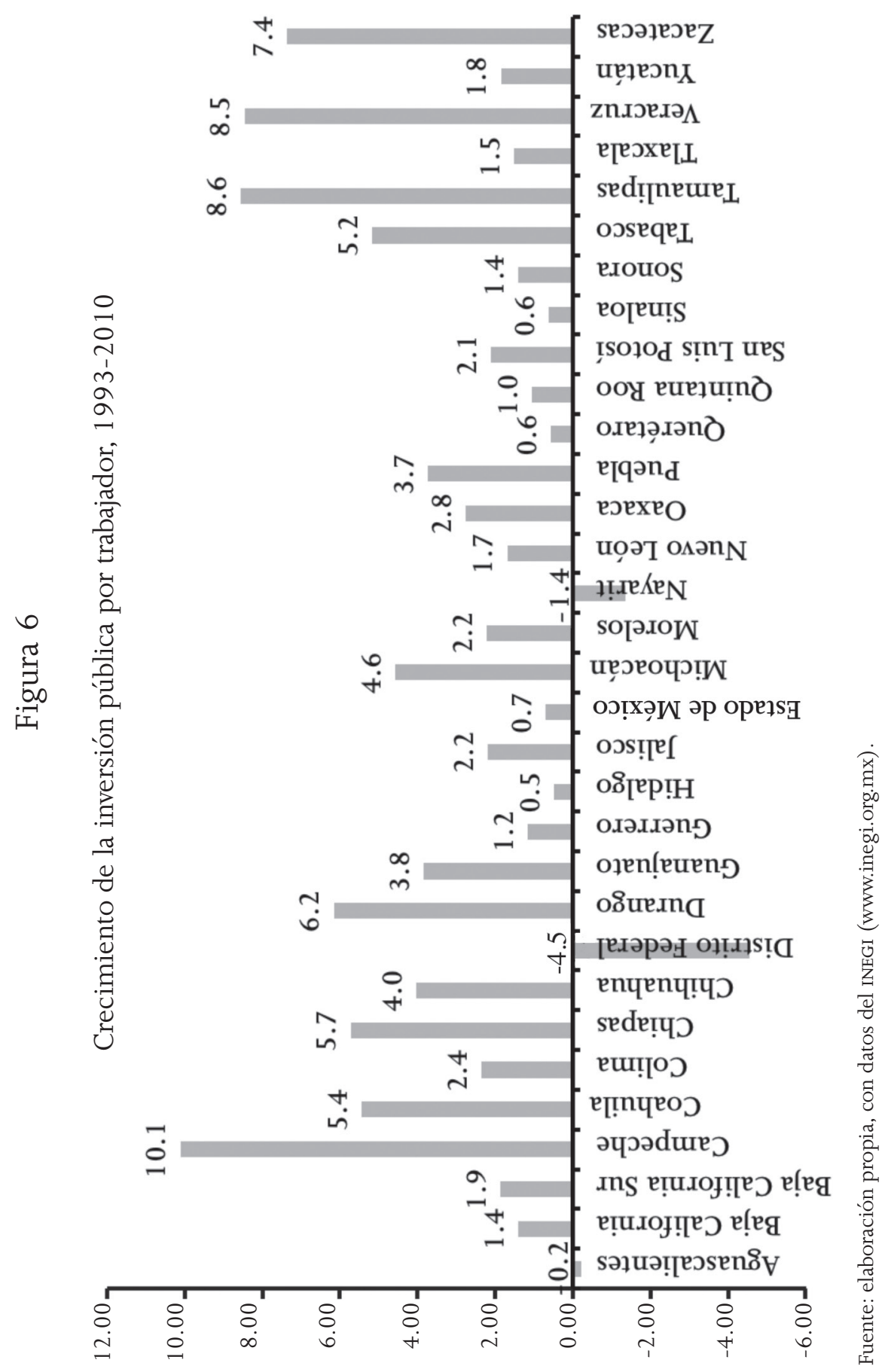




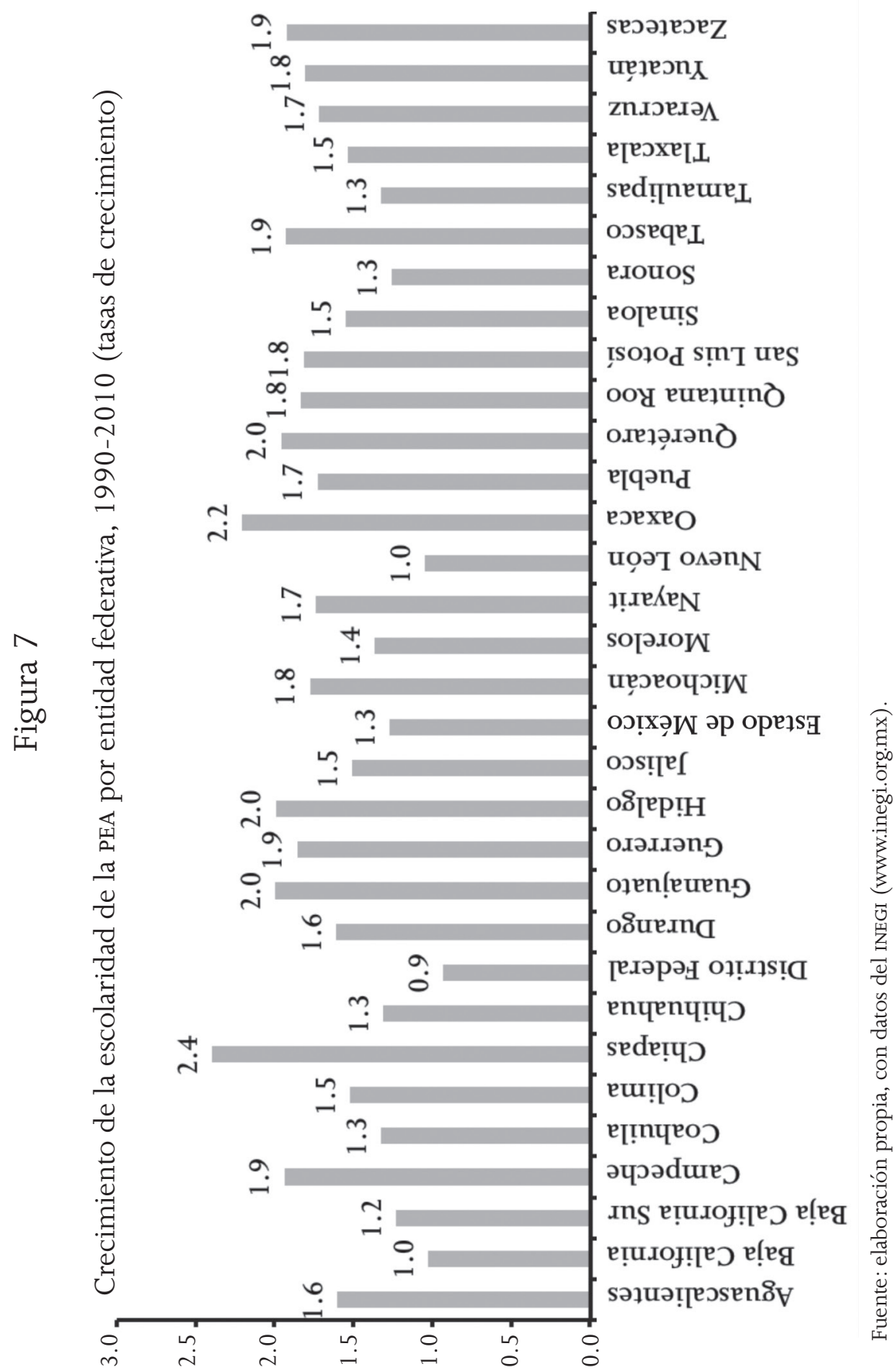


utiliza para aproximar el capital humano acumulado por trabajador, mientras que el segundo se usa como proxy de las tasas de inversión que realiza la sociedad en la producción de este factor (Barro 1997). La escolaridad de la PEA aumenta a tasas relativamente homogéneas en la mayoría de las entidades, o por lo menos no se observa la dispersión en las tasas de crecimiento de la inversión (véase figura 7).

Un aspecto que dejan claro los datos disponibles, sobre todo si se considera lo avanzado en cuanto a la cobertura en todos los niveles escolares, es que el crecimiento lento de la productividad, característico de México, no obedece a una formación lenta de capital humano, ni a una escasez en la disponibilidad de este recurso. Por el contrario, las tasas a las que se ha generado capital humano adicional son altas y en todo caso estarían reflejando ausencia de capacidades productivas para aprovecharlo de manera eficiente, quizá por las dificultades para abrir fuentes de empleo en sectores intensivos en el uso de este factor. De la misma manera, las diferencias observadas entre los estados no parecen ser un elemento de peso para explicar sus desempeños económicos desiguales.

\section{El rol de la especialización}

Una hipótesis razonable con respecto a la desaceleración en el incremento del producto por trabajador, es que ésta obedece a una pérdida de peso relativo dentro del empleo, de los sectores y actividades con alta productividad y capacidad de arrastre sobre el conjunto de la economía, como la industria manufacturera, cuya contraparte es una expansión en los servicios tradicionales y la informalidad. Según esta idea, el aumento rápido de la PEA en un contexto de crecimiento lento de la inversión implicó que la nueva mano de obra disponible no encontrara espacios laborales en el sector formal, y se orientara a la informalidad.

La información presentada en la figura 8 soporta la existencia de tres grandes tendencias, que se perfilan en el periodo 1996-2010: ${ }^{5}$

\footnotetext{
${ }^{5}$ En este ejercicio y en otros para los que no hay información desde 1993, se utiliza la del periodo 1996-2010.
} 
a) una contracción relativa del sector primario, que se observa en todas las entidades y que en la mayoría de ellas se acompaña con una reducción de puestos de trabajo en términos absolutos, con excepción de Baja California, Morelos, Nayarit y Querétaro, en donde éstos continúan expandiéndose; b) una caída en la participación del ramo manufacturero, que si bien en el plano nacional es de apenas un poco más de un punto porcentual, en algunos estados llega a ser significativo, como en Chihuahua (5.2), Durango (5.1), Coahuila (3.9), Nuevo León (3.7), Baja California (3.3), Baja California Sur (3.3) y Quintana Roo (3.3). Esta caída ocurre en un contexto en que el empleo sectorial aumenta en términos absolutos en la mayoría de las entidades, aunque a una tasa menor que la del empleo total y c) un proceso de terciarización que avanza de manera firme a lo largo del país, y que se manifiesta con una expansión acelerada de la ocupación a tasas anuales de 3.0 por ciento en promedio, que destaca en Quintana Roo (7.4), Baja California Sur (5.1), Puebla (4.3), Aguascalientes (4.0), Querétaro (3.9), Baja California (3.8) y Campeche (3.8). Este proceso se alimenta de la contracción del sector primario, sobre todo de la expansión acelerada de la PEA que caracteriza el periodo de estudio.

El proceso de terciarización, ilustrado por estos datos, permite entender la desaceleración en el crecimiento de la productividad del trabajo, a que se ha hecho alusión en párrafos anteriores, pues es sabido que las actividades terciarias suelen ser menos dinámicas que las manufactureras en cuanto a capacidad de innovación, y para incorporar el progreso técnico (Rowthorn y Ramaswamy 1997). Esto es así, aun cuando algunos servicios como los profesionales, los financieros y las comunicaciones son intensivos en tecnología y capital humano, debido a que los trabajos de baja productividad, que se agrupan dentro del comercio, restaurantes y hoteles, del hogar y los informales tienen un peso elevado en la composición del empleo sectorial.

El hogar es un buen representante de las tareas poco productivas, pues agrupa a las asociadas con la explotación de pequeñas parcelas ejidales, producción artesanal, comercio minorista, ambulantaje, trasporte de carga y taxis, así como reparaciones diversas, servicios domésticos y sexo servicios, muchas de las cuales pueden realizarse 


\section{Figura 8}

\section{Distribución sectorial del personal ocupado (porcentajes)}

\begin{tabular}{|c|c|c|c|c|c|c|c|c|c|c|c|c|}
\hline & \multicolumn{3}{|c|}{ Primario } & \multicolumn{3}{|c|}{ Secundario } & \multicolumn{3}{|c|}{ Manufacturas } & \multicolumn{3}{|c|}{ Terciario } \\
\hline & 1996 & 2010 & $\mathrm{TCA}^{*}$ & 1996 & 2010 & $\mathrm{TCA}^{*}$ & 1996 & 2010 & $\mathrm{TCA}^{*}$ & 1996 & 2010 & $\mathrm{TCA}^{*}$ \\
\hline Aguascalientes & 14.1 & 5.9 & -3.2 & 29.2 & 29.2 & 3.0 & 21.3 & 20.8 & 2.8 & 56.7 & 64.9 & 4.0 \\
\hline Baja California & 8.0 & 6.3 & 1.5 & 31.5 & 28.0 & 2.3 & 22.8 & 19.5 & 2.0 & 60.6 & 65.7 & 3.8 \\
\hline $\begin{array}{l}\text { Baja California } \\
\text { Sur }\end{array}$ & 20.3 & 8.1 & -2.8 & 18.9 & 19.4 & 4.0 & 10.5 & 7.2 & 1.1 & 60.9 & 72.5 & 5.1 \\
\hline Campeche & 31.9 & 20.0 & -0.7 & 17.3 & 20.4 & 3.8 & 6.6 & 9.1 & 5.0 & 50.8 & 59.5 & 3.8 \\
\hline Coahuila & 9.1 & 5.2 & -2.3 & 36.3 & 31.4 & 0.6 & 26.2 & 22.3 & 0.5 & 54.6 & 63.4 & 2.7 \\
\hline Colima & 18.2 & \begin{tabular}{|l|}
11.7 \\
\end{tabular} & -0.3 & 20.1 & 18.9 & 2.4 & 10.6 & 8.6 & 1.3 & 61.7 & 69.3 & 3.7 \\
\hline Chiapas & 53.7 & 38.3 & -0.9 & 10.8 & \begin{tabular}{|l|}
14.7 \\
\end{tabular} & 3.8 & 6.2 & 8.0 & 3.4 & 35.6 & 47.0 & 3.6 \\
\hline Chihuahua & 15.7 & 10.4 & -1.8 & 35.2 & 30.5 & 0.1 & 27.1 & 21.9 & -0.4 & 49.0 & 59.0 & 2.5 \\
\hline Distrito Federal & 1.0 & 0.4 & -6.1 & 19.9 & 18.2 & 0.3 & 14.9 & 12.4 & -0.4 & 79.1 & 81.4 & 1.2 \\
\hline Durango & \begin{tabular}{|l|}
23.1 \\
\end{tabular} & \begin{tabular}{|l|}
16.7 \\
\end{tabular} & -1.3 & 27.3 & \begin{tabular}{|l|}
24.8 \\
\end{tabular} & 0.3 & 20.0 & 14.9 & -1.1 & 49.6 & 58.5 & 2.2 \\
\hline $\begin{array}{l}\text { Estado de } \\
\text { México }\end{array}$ & 11.4 & 5.0 & -3.4 & 29.1 & 26.8 & 1.8 & 19.7 & 17.3 & 1.5 & 59.5 & 68.3 & 3.5 \\
\hline Guanajuato & 22.7 & 10.6 & -3.5 & 31.2 & 32.1 & 2.1 & 24.0 & 24.3 & 1.9 & 46.1 & 57.2 & 3.4 \\
\hline Guerrero & 42.0 & 31.1 & -0.7 & 14.5 & 16.7 & 2.4 & 7.2 & 10.4 & 4.2 & 43.5 & 52.2 & 2.7 \\
\hline Hidalgo & 39.2 & 21.6 & -2.9 & 21.4 & 25.2 & 2.5 & 14.1 & 14.8 & 1.7 & 39.5 & 53.1 & 3.5 \\
\hline Jalisco & 19.1 & 9.1 & -3.4 & 27.7 & 26.4 & 1.5 & 20.2 & 18.3 & 1.2 & 53.1 & 64.5 & 3.3 \\
\hline Michoacán & 35.9 & 20.4 & -3.3 & 21.0 & 21.2 & 0.8 & 14.2 & 13.0 & 0.0 & 43.2 & 58.4 & 2.9 \\
\hline Morelos & 15.0 & 11.1 & 0.3 & 25.0 & 22.8 & 1.8 & 13.3 & 12.0 & 1.8 & 60.0 & 66.1 & 3.2 \\
\hline Nayarit & 26.9 & 21.5 & 0.0 & 16.2 & 16.3 & 1.7 & 8.7 & 8.5 & 1.5 & 57.0 & 62.2 & 2.2 \\
\hline Nuevo León & 6.2 & 2.4 & -4.4 & 32.4 & 29.9 & 1.9 & 24.0 & 20.3 & 1.2 & 61.4 & 67.7 & 3.2 \\
\hline Oaxaca & 49.7 & 31.8 & -0.7 & 15.1 & 19.9 & 3.2 & 9.4 & 12.8 & 3.5 & 35.2 & 48.3 & 3.5 \\
\hline Puebla & 34.0 & 22.1 & -3.6 & 25.6 & 25.4 & 2.3 & 19.3 & 17.3 & 1.6 & 40.4 & 52.5 & 4.3 \\
\hline Querétaro & 18.1 & 7.3 & 1.2 & 29.0 & 32.2 & 3.6 & 18.9 & 21.4 & 3.8 & 52.9 & 60.5 & 3.9 \\
\hline Quintana Roo & 13.4 & 6.6 & -0.1 & 17.0 & 14.1 & 5.0 & 9.1 & 5.8 & 3.1 & 69.7 & 79.2 & 7.4 \\
\hline San Luis Potosí & 27.3 & 20.1 & -0.9 & 23.0 & 23.5 & 2.3 & 14.5 & 16.2 & 2.9 & 49.6 & 56.4 & 3.1 \\
\hline Sinaloa & 27.0 & \begin{tabular}{|l|}
18.9 \\
\end{tabular} & -4.3 & 20.0 & 18.1 & 1.0 & 11.5 & 9.6 & 0.4 & 53.0 & 63.0 & 3.0 \\
\hline Sonora & 21.7 & 9.8 & -2.3 & 24.8 & 28.3 & 2.3 & 15.1 & 18.5 & 2.8 & 53.5 & 61.9 & 2.4 \\
\hline Tabasco & 31.3 & 17.9 & -2.5 & 17.9 & 20.9 & 2.7 & 9.2 & 7.1 & -0.2 & 50.8 & 61.2 & 3.0 \\
\hline Tamaulipas & 12.4 & 6.7 & -0.4 & 27.0 & 30.0 & 2.6 & 18.2 & 18.7 & 2.0 & 60.6 & 63.3 & 2.2 \\
\hline Tlaxcala & 25.0 & \begin{tabular}{|l|}
17.9 \\
\end{tabular} & -1.4 & 31.3 & 31.7 & 2.1 & 24.6 & 22.4 & 1.3 & 43.6 & 50.4 & 3.1 \\
\hline Veracruz & 32.5 & 22.7 & -0.5 & 17.6 & 19.5 & 1.9 & 11.7 & 9.9 & 0.0 & 49.9 & 57.8 & 2.2 \\
\hline Yucatán & \begin{tabular}{|l|}
17.9 \\
\end{tabular} & 10.9 & -1.7 & 25.5 & 27.3 & 3.5 & 17.2 & 18.5 & 3.6 & 56.6 & 61.8 & 3.7 \\
\hline Zacatecas & 36.9 & 25.5 & -0.7 & 20.9 & 20.2 & 0.7 & 9.4 & 10.5 & 1.8 & 42.2 & 54.3 & 2.8 \\
\hline Nacional & 22.2 & 13.3 & -1.8 & 24.2 & 24.1 & 1.8 & 16.7 & 15.5 & 1.4 & 53.7 & 62.6 & 3.0 \\
\hline
\end{tabular}

* Representa el aumento en el número de personas, no en los porcentajes de participación.

Nota: el sector secundario incluye a la manufactura. Todos los porcentajes de participación se refieren al empleo del sector con respecto al empleo total del estado.

Fuente: INEGI (2010 y 1996). 
dentro de la informalidad o de manera formal, pero cuya característica principal es el uso reducido o nulo de capital y la obtención de beneficios rápidos. Entre 1996 y 2012, este sector redujo su contribución relativa a la ocupación total, de 38.1 a 36.2 por ciento, cuando se considera el país en su conjunto, pero su crecimiento en términos absolutos no fue menor: 1.8 por ciento anual contra 2.1, si se agrupa al resto de las actividades económicas. En lo que respecta a los estados, su comportamiento es heterogéneo, al menos hay tres grupos con características distintivas; el primero engloba a aquéllos en donde este tipo de labores pierde importancia relativa y la ocupación que generan crece poco o decrece, como en Chiapas, Chihuahua, Jalisco, Michoacán, San Luis Potosí, Sinaloa, Veracruz y Zacatecas. Como contraparte, sus tasas de crecimiento de la ocupación son relativamente altas en el resto de actividades económicas (véase figura 9).

Un segundo grupo, integrado por Baja California, Campeche, Colima, Guanajuato, Estado de México, Morelos, Nayarit, Nuevo León, Querétaro, Quintana Roo y Tamaulipas se caracteriza por una contracción relativa del sector del hogar, que se acompaña con un aumento rápido del personal que labora dentro de éste. El resto de las entidades conforman un tercer grupo en donde la participación porcentual de la ocupación en las actividades del hogar aumenta y paralelamente se registra un crecimiento alto del personal ocupado. Este es el caso de Aguascalientes, Baja California Sur, Coahuila, Distrito Federal, Durango, Guerrero, Hidalgo, Oaxaca, Puebla, Sonora, Tabasco, Tlaxcala y Yucatán.

Si se compara el crecimiento en el producto por trabajador, mostrado por cada uno de estos grupos, se puede establecer que el primero es el que tiene mejor desempeño con una tasa anual promedio de 0.5 por ciento en el periodo 1993-2010, y cinco de ocho estados crecieron por encima de la media nacional. El grupo con peor desempeño fue el segundo, con -0.3 por ciento anual y sólo cuatro de once entidades crecieron por arriba del promedio del país. El tercer grupo registró valores intermedios, de 0.2 por ciento y seis de trece avanzaron más rápido que el promedio nacional. Estas cifras sugieren que el crecimiento lento guarda un vínculo positivo con el peso relativo y dinamismo del empleo en sectores de baja productividad, pero 


\section{Figura 9}

Distribución del personal ocupado en el sector del hogar por entidad federativa (porcentajes)

\begin{tabular}{|c|c|c|c|c|c|c|}
\hline & \multicolumn{3}{|c|}{$\begin{array}{l}\text { Sector del hogar } \\
\quad \text { (\% de PO) }\end{array}$} & \multicolumn{3}{|c|}{$\begin{array}{l}\text { Sector no hogar } \\
\quad(\% \text { de } \mathrm{PO})\end{array}$} \\
\hline & 1996 & 2010 & $\mathrm{TCA}^{*}$ & 1996 & 2010 & $\mathrm{TCA}^{*}$ \\
\hline Aguascalientes & 28.5 & 29.2 & 3.2 & 71.5 & 70.8 & 2.9 \\
\hline Baja California & 23.6 & 21.9 & 3.1 & 76.4 & 78.1 & 3.8 \\
\hline Baja California Sur & 24.0 & 25.6 & 4.3 & 76.0 & 74.4 & 3.7 \\
\hline Campeche & 38.0 & 34.6 & 2.0 & 62.0 & 65.4 & 3.0 \\
\hline Coahuila & 29.4 & 30.1 & 1.8 & 70.6 & 69.9 & 1.6 \\
\hline Colima & 31.1 & 25.5 & 1.5 & 68.9 & 74.5 & 3.5 \\
\hline Chiapas & 44.8 & 34.9 & -0.2 & 55.2 & 65.1 & 2.8 \\
\hline Chihuahua & 26.4 & 23.2 & 0.4 & 73.6 & 76.8 & 1.7 \\
\hline Distrito Federal & 31.4 & 32.7 & 1.2 & 68.6 & 67.3 & 0.8 \\
\hline Durango & 32.7 & 33.6 & 1.2 & 67.3 & 66.4 & 0.9 \\
\hline Estado de México & 43.5 & 39.6 & 1.8 & 56.5 & 60.4 & 3.0 \\
\hline Guanajuato & 40.3 & 37.4 & 1.3 & 59.7 & 62.6 & 2.2 \\
\hline Guerrero & 51.4 & 61.0 & 2.7 & 48.6 & 39.0 & -0.2 \\
\hline Hidalgo & 40.9 & 45.9 & 2.2 & 59.1 & 54.1 & 0.7 \\
\hline Jalisco & 38.5 & 32.5 & 0.7 & 61.5 & 67.5 & 2.6 \\
\hline Michoacán & 47.6 & 39.2 & -0.7 & 52.4 & 60.8 & 1.8 \\
\hline Morelos & 46.3 & 40.8 & 1.5 & 53.7 & 59.2 & 3.2 \\
\hline Nayarit & 35.1 & 33.0 & 1.2 & 64.9 & 67.0 & 1.9 \\
\hline Nuevo León & 30.2 & 28.4 & 2.0 & 69.8 & 71.6 & 2.6 \\
\hline Oaxaca & 47.2 & 60.4 & 3.0 & 52.8 & 39.6 & -0.8 \\
\hline Puebla & 42.7 & 44.9 & 2.8 & 57.3 & 55.1 & 2.1 \\
\hline Querétaro & 38.2 & 30.5 & 1.2 & 61.8 & 69.5 & 3.7 \\
\hline Quintana Roo & 35.1 & 32.0 & 5.7 & 64.9 & 68.0 & 6.8 \\
\hline San Luis Potosí & 40.8 & 30.8 & 0.1 & 59.2 & 69.2 & 3.3 \\
\hline Sinaloa & 30.5 & 25.7 & 0.5 & 69.5 & 74.3 & 2.2 \\
\hline Sonora & 25.8 & 27.5 & 1.9 & 74.2 & 72.5 & 1.3 \\
\hline Tabasco & 35.7 & 35.8 & 1.7 & 64.3 & 64.2 & 1.6 \\
\hline Tamaulipas & 33.4 & 29.8 & 1.1 & 66.6 & 70.2 & 2.4 \\
\hline Tlaxcala & 44.5 & 47.3 & 2.5 & 55.5 & 52.7 & 1.6 \\
\hline Veracruz & 39.6 & 36.3 & 0.6 & 60.4 & 63.7 & 1.6 \\
\hline Yucatán & 42.3 & 43.4 & 3.2 & 57.7 & 56.6 & 2.9 \\
\hline Zacatecas & 36.8 & 31.8 & -0.1 & 63.2 & 68.2 & 1.5 \\
\hline Nacional & 38.1 & 36.2 & 1.8 & 61.9 & 63.8 & 2.1 \\
\hline
\end{tabular}

* Representa el aumento en el número de personas, no de los porcentajes. Fuente: INEGI (1970 y 1996). 
también son ilustrativas de que existen otros factores que pueden atenuar o acentuar esta relación.

\section{Diferencias en desempeño económico}

\section{y sus determinantes}

Determinación y estimación del modelo

Con la finalidad de identificar los factores que explican las diferencias en desempeño económico entre las entidades federativas, se realizaron algunos ejercicios econométricos, para lo cual se formuló una función que toma como variable dependiente la tasa de crecimiento del producto por trabajador, y cuyos determinantes se seleccionaron siguiendo la teoría, y quedó como sigue:

$$
\mathrm{g}_{\mathrm{p}}=\mathrm{F}(\mathrm{k}, \mathrm{h}, \mathrm{\chi})
$$

en donde $g_{p}$ corresponde a la TCA_PIB/PO, $\mathrm{k}$ se refiere al capital físico y h al humano por trabajador, los cuales pueden expresarse en niveles o en tasas de crecimiento, $\chi$ engloba a otros factores relevantes que inciden sobre $g_{p}$. Fue necesario construir variables proxies, debido a que algunas de las requeridas no están disponibles en las estadísticas oficiales. De esta manera, k se aproxima a la inversión física del sector público federal (IPF) en cada entidad; el gasto de los gobiernos estatales en obras y fomento (IPE); la inversión pública total (IPT), que surge de sumar las anteriores, y la inversión extranjera directa (IED); en los cuatro casos, ponderadas entre la población ocupada. De la misma forma, con h se recurre al porcentaje de la población ocupada con educación básica (PO_EDUC_BAS), con media superior (PO_EDUC_MSUP) y superior (PO_EDUC_SUP). ${ }^{6}$

Para incluir fenómenos que han incidido en las experiencias de desarrollo regional, se agregaron variables representativas de $\chi$ como la tasa de migración neta (TMN) y el porcentaje de la población ocupada que labora en el sector del hogar (PO_HOGAR), con la finalidad

\footnotetext{
${ }^{6}$ Cada una de las variables puede estar antecedida por la sigla TCA.
} 
de medir el efecto asociado a la proliferación de actividades de baja productividad. Además, se usó el logaritmo natural del producto por trabajador del año inicial (LPIBPO_93), para capturar el efecto emparejamiento tecnológico (catch up); la distancia existente entre la capital de cada estado, con respecto a la ciudad fronteriza del norte más cercana (DIST_FRONT), para medir los posibles efectos regionales de la apertura comercial, así como una variable dicotómica (D_CAMP), para controlar el comportamiento atípico observado en Campeche.

También se formuló una segunda función para la tasa de crecimiento de la ocupación, que se dividió en el sector del hogar (TCA HOGAR) y los restantes (TCA_PO_NOHOGAR), la cual se definió como:

$$
g_{\mathrm{L}}=\mathrm{L}(\mathrm{I}, \Omega)
$$

donde I se refiere a la inversión en capital físico o a alguna proxy, entre las que se definieron antes, y $\Omega$ juega el mismo rol que $\chi$ en la ecuación 1.

En todos los casos se usó el método de prueba y error hasta encontrar la mejor especificación, que fue la única que se reportó. Las variables que no resultaron significativas sólo se presentaron en una de las ecuaciones estimadas y se eliminaron en las siguientes. La información se tomó de las bases de datos del INEGi (www.inegi.org. $\mathrm{mx}$ ), excepto la inversión pública federal, obtenida de los informes de la Presidencia de la república, y la variable DIST_FRONT, que se construyó con datos disponibles en la página electrónica de Caminos y Puentes Federales. Los primeros ejercicios estimaron la función 1, con datos de sección cruzada, para el periodo 1993-2010 y con datos de panel divididos en tres subperiodos determinados arbitrariamente cuidando que no fueran menores a cinco años, pues se trataba de capturar relaciones que es difícil observar en lapsos muy cortos. Se seleccionaron los subperiodos 1993-2000, 2000-2005 y 2005$2010 .^{7}$ En el primer caso, los resultados se muestran en la figura 10, mediante especificaciones alternativas, en donde se puede observar

\footnotetext{
7 También se probaron periodizaciones distintas como: 1993-1999, 1999-2005 y 20052010, con resultados muy similares a los que se presentan en la figura 12 .
} 
Figura 10

Función de crecimiento del PIB por trabajador

(datos de sección cruzada)

\begin{tabular}{|c|c|c|c|c|c|c|c|}
\hline & & \multicolumn{6}{|c|}{ Variable dependiente: TCA_PIB/PO 1993-2010 } \\
\hline Constante & $\begin{array}{c}0.80 \\
(0.16)\end{array}$ & $\begin{array}{c}0.78 \\
(1.72)^{*}\end{array}$ & $\begin{array}{c}0.65 \\
(1.99)^{*}\end{array}$ & $\begin{array}{c}-3.20 \\
(-1.67)^{*}\end{array}$ & $\begin{array}{l}-11.27 \\
(-4.37)\end{array}$ & $\begin{array}{c}1.17 \\
(2.19)^{* *}\end{array}$ & $\begin{array}{c}-2.82 \\
(-3.04)^{* * *}\end{array}$ \\
\hline LPIBPO_93 & $\begin{array}{c}-0.10 \\
(-0.21)\end{array}$ & & & & & & \\
\hline DIST_FRONT_N & & $\begin{array}{c}-1.99 \\
(-2.40)^{* *}\end{array}$ & $\begin{array}{c}-1.84 \\
(-3.56)^{* * *}\end{array}$ & $\begin{array}{c}-2.04 \\
(-2.51)^{* *}\end{array}$ & & & \\
\hline $\begin{array}{c}\text { TCA_IPT/PO } \\
(\mathrm{t})\end{array}$ & $\begin{array}{c}0.13 \\
(3.41)^{* * *}\end{array}$ & $\begin{array}{c}0.11 \\
(2.77)^{* * *}\end{array}$ & $\begin{array}{c}0.06 \\
(1.80)^{*}\end{array}$ & $\begin{array}{c}0.07 \\
(1.79)^{*}\end{array}$ & $\begin{array}{c}0.07 \\
(2.04)^{* *}\end{array}$ & $\begin{array}{c}0.08 \\
(1.88)^{*}\end{array}$ & \\
\hline TCA_IED/PO & & & & & & & $\begin{array}{c}0.01 \\
(2.61)^{* *}\end{array}$ \\
\hline $\begin{array}{l}\text { TMN } \\
(\mathrm{t})\end{array}$ & & & $\begin{array}{c}-0.45 \\
(-2.87)^{* * *}\end{array}$ & & $\begin{array}{c}-0.46 \\
(-2.17)\end{array}$ & $\begin{array}{c}-0.66 \\
(-3.01)^{* * *}\end{array}$ & $\begin{array}{c}-0.73 \\
(-3.69)^{* * *}\end{array}$ \\
\hline $\begin{array}{c}\text { PO_EDUC_BAS } \\
(\mathrm{t})\end{array}$ & & & & $\begin{array}{c}0.07 \\
(2.12)^{* *}\end{array}$ & $\begin{array}{c}0.14 \\
(3.94)^{* * *}\end{array}$ & & \\
\hline $\begin{array}{c}\text { PO_EDUC_SUP } \\
(\mathrm{t})\end{array}$ & & & & & $\begin{array}{c}0.15 \\
(4.12)^{* * *}\end{array}$ & & \\
\hline $\begin{array}{c}\text { PO_HOGAR } \\
(\mathrm{t})\end{array}$ & & & & & & $\begin{array}{c}-0.04 \\
(-3.24)^{* * *}\end{array}$ & \\
\hline $\begin{array}{c}\text { PO_NO_HOGAR } \\
(\mathrm{t})\end{array}$ & & & & & & & $\begin{array}{c}0.04 \\
(2.72)^{* * *}\end{array}$ \\
\hline $\begin{array}{c}\text { D_CAMP } \\
(\mathrm{t})\end{array}$ & $\begin{array}{c}-3.71 \\
(-8.24)^{* * *}\end{array}$ & $\begin{array}{c}-2.79 \\
(-6.26)^{* * *}\end{array}$ & $\begin{array}{c}-2.36 \\
(-6.78)^{* * *}\end{array}$ & $\begin{array}{c}-2.44 \\
(-5.38)^{* * *}\end{array}$ & $\begin{array}{c}-3.05 \\
(-11.49)^{* * *}\end{array}$ & $\begin{array}{c}-3.22 \\
(-10.33)^{* * *}\end{array}$ & $\begin{array}{c}-2.66 \\
(-18.50)^{* * *}\end{array}$ \\
\hline $\mathrm{R}^{2}$ ajustado & 0.34 & 0.55 & 0.66 & 0.58 & 0.61 & 0.58 & 0.57 \\
\hline D. W & 2.35 & 2.29 & 2.17 & 2.35 & 2.29 & 2.36 & 2.16 \\
\hline F & 6.22 & 13.38 & 16.34 & 11.89 & 10.78 & 11.82 & 11.30 \\
\hline $\begin{array}{c}\text { Jarque Bera } \\
\rho\end{array}$ & $\begin{array}{c}8.97 \\
(0.01)\end{array}$ & $\begin{array}{c}2.77 \\
(0.25)\end{array}$ & $\begin{array}{c}0.78 \\
(0.68)\end{array}$ & $\begin{array}{c}5.84 \\
(0.05)\end{array}$ & $\begin{array}{c}0.34 \\
(0.84)\end{array}$ & $\begin{array}{c}0.00 \\
(0.99)\end{array}$ & $\begin{array}{c}2.90 \\
(0.23)\end{array}$ \\
\hline $\begin{array}{l}\text { Breusch- } \\
\text { Godfrey } \\
\text { (LM) } \\
\rho\end{array}$ & $\begin{array}{c}1.16 \\
(0.33)\end{array}$ & $\begin{array}{c}0.87 \\
(0.43)\end{array}$ & $\begin{array}{c}0.71 \\
(0.50)\end{array}$ & $\begin{array}{c}0.86 \\
(0.44)\end{array}$ & $\begin{array}{c}0.68 \\
(0.51)\end{array}$ & $\begin{array}{c}1.12 \\
(0.34)\end{array}$ & $\begin{array}{c}0.41 \\
(0.67)\end{array}$ \\
\hline $\begin{array}{c}\text { Breusch- } \\
\text { Pagan-Godfrey } \\
\rho\end{array}$ & $\begin{array}{c}1.06 \\
(0.38)\end{array}$ & $\begin{array}{c}0.66 \\
(0.58)\end{array}$ & $\begin{array}{c}1.58 \\
(0.21)\end{array}$ & $\begin{array}{c}1.15 \\
(0.35)\end{array}$ & $\begin{array}{c}1.66 \\
(0.18)\end{array}$ & $\begin{array}{c}1.49 \\
(0.23)\end{array}$ & $\begin{array}{c}0.15 \\
(0.96)\end{array}$ \\
\hline $\mathrm{N}$ & 32 & 32 & 32 & 32 & & 32 & 32 \\
\hline
\end{tabular}

Nota: PO_EDUC_BAS, PO_EDUC_SUP y TMN corresponden a promedios del periodo 1990-2010, al igual que PO_HOGAR y PO_NO_HOGAR, aunque en este caso del 1996-2010.

${ }^{*}$ Significativa a $10 \%,{ }^{* *}$ significativa a $5 \%$ y ${ }^{* * *}$ significativa a $1 \%$.

Fuente: estimaciones propias. 
que todas las variables arrojan el signo esperado; además, el ajuste entre los datos medido por el $\mathrm{R}^{2}$ ajustado es razonablemente alto en seis de las siete especificaciones y las pruebas de robustez del modelo denotan ausencia de anormalidad, heterocedasticidad y autocorrelación en los residuos de la regresión, por lo menos en seis de ellas.

En relación con la inversión por trabajador, las variables proxies que arrojaron un buen ajuste fueron la TCA_ IPT/PO y la TCA_ IED/PO, ambas tuvieron un efecto positivo sobre TCA_ PIB/PO. Las variables que capturan el impacto del capital humano por trabajador: (PO_ EDUC_BAS Y PO_EDUC_SUP) arrojaron también un signo positivo. Por su parte, PO_HOGAR y PO_NO_HOGAR, ${ }^{8}$ como era de esperarse, inciden de forma negativa y positiva en la variable dependiente, mientras que TMN mantiene una relación inversa con ésta. La variable dicotómica utilizada para aislar a Campeche es altamente significativa, lo que confirma su comportamiento atípico. Algo similar ocurre con el coeficiente asociado a la variable DIST_FRONT, cuyo signo negativo refleja por un lado la importancia de la localización geográfica y de manera más específica de la cercanía con Estados Unidos y, por otro, la influencia que han tenido las ventajas naturales con las que cuenta cada entidad en la agudización de las diferencias regionales, para integrarse con éxito al mercado mundial.

Si bien los resultados obtenidos parecen econométricamente sólidos, es necesaria evidencia adicional que confirme si el modelo utilizado es el adecuado. Por ello, se procedió a estimar uno de panel con efectos fijos, cuyo principal supuesto es que existen efectos temporales o asociados a cada entidad, que no son recogidos por las variables del modelo. Se aplicó el test de máxima verosimilitud para la redundancia de los efectos fijos en sección cruzada y en periodo. De acuerdo con los valores $\rho$ obtenidos, y al considerar que la regla de decisión establece que este modelo se rechaza si $\rho>0.05$, se asume que los interceptos son iguales, tanto para los datos de sección cruzada como para los de periodo (véase figura 11). Esto implica que el modelo correcto es el de datos agrupados con intercepto común, el cual se estima por mínimos cuadrados ordinarios.

\footnotetext{
8 PO_NO_HOGAR es el residuo en términos porcentuales entre la ocupación total $(100 \%)$ y la correspondiente al sector del hogar.
} 


\section{Figura 11}

Pruebas de selección del modelo con datos de panel

\begin{tabular}{|c|c|c|c|}
\hline \multicolumn{4}{|c|}{$\begin{array}{c}\text { Efectos fijos redundantes } \\
\text { Test de máxima verosimilitud }\end{array}$} \\
\hline & $\begin{array}{c}\text { Efectos fijos } \\
\text { sección cruzada }\end{array}$ & $\begin{array}{c}\text { Efectos fijos } \\
\text { periodo }\end{array}$ & $\begin{array}{c}\text { Efectos } \\
\text { conjuntos }\end{array}$ \\
\hline Estadístico F & 1.40 & 1.80 & 1.50 \\
\hline Grados de libertad & $(31,58)$ & $(2,87)$ & $(33,56)$ \\
\hline Probabilístico $(\rho)$ & 0.13 & 0.17 & 0.09 \\
\hline
\end{tabular}

Nota: periodos utilizados: 1993-2000, 2000-2005 y 2005-2010.

Fuente: estimaciones propias.

La estimación se realizó con algunas variantes con respecto al ejercicio anterior, primero se adicionó la variable PIBPO_INI, que captura el efecto emparejamiento tecnológico y que en el caso precedente no fue significativa ni tuvo el signo esperado. Su signo negativo revela que la dinámica de la TCA_PIB/PO está influida por una tendencia de las economías atrasadas por alcanzar a las líderes, una vez que se controla por otros factores, debido al hecho de que es más fácil acceder a mejores técnicas productivas cuando se está en una situación de atraso, que al estar cerca de la frontera tecnológica. Para mejorar el ajuste de los datos también fue necesario agregar una variable dicotómica para Campeche, que aísla sólo el periodo 2005-2010, en donde se registran valores atípicos. Los resultados son similares a los de la figura 10 (véase figura 12).

En cuanto a la estimación de la ecuación 6, considera dos versiones que toman como variables dependientes a la TCA_POHOGAR y la TCA_PO_NOHOGAR, asimismo $\Omega$ se representa con la TMN, la PO_ EDUC_BAS y la PO_EDUC_SUP. La primera incide en la dinámica de la ocupación a través de sus repercusiones sobre la PEA, mientras que las otras dos influyen en el tipo de empleos que se crean. En este caso sólo se reportan los resultados con datos de sección cruzada, toda vez que las pruebas de máxima verosimilitud para efectos fijos redundantes arrojaron que el modelo correcto era el de intercepto común. De acuerdo con esta evidencia, el coeficiente de TMN registra la mayor significancia estadística, con signo positivo para las dos variables usadas para representar la dinámica de la ocupación. Por su parte, 


\section{Figura 12}

Función de crecimiento del PIB por trabajador (datos agrupados con intercepto común)

\begin{tabular}{|c|c|}
\hline \multicolumn{2}{|c|}{ Variable dependiente: TCA_PIB/PO } \\
\hline & $\begin{array}{l}\text { Mínimos cuadrados ordinarios } \\
\text { (datos agrupados en tres periodos) }\end{array}$ \\
\hline $\begin{array}{l}\text { Constante } \\
(\mathrm{t})\end{array}$ & $\begin{array}{c}-6.38 \\
(-1.66)^{*}\end{array}$ \\
\hline $\begin{array}{c}\text { TCA_(IPT/PO) } \\
(\mathrm{t})\end{array}$ & $\begin{array}{c}0.02 \\
(1.72)^{*}\end{array}$ \\
\hline $\begin{array}{c}\text { PO_EDUC_BAS } \\
(\mathrm{t})\end{array}$ & $\begin{array}{l}0.10 \\
(2.27)^{* *}\end{array}$ \\
\hline $\begin{array}{c}\text { PO_EDUC_SUP } \\
(\mathrm{t})\end{array}$ & $\begin{array}{l}0.16 \\
(3.34)^{* * *}\end{array}$ \\
\hline $\begin{array}{l}\text { TMN } \\
(\mathrm{t})\end{array}$ & $\begin{array}{c}-0.62 \\
(-3.65)^{* * *}\end{array}$ \\
\hline $\begin{array}{c}\text { PO_HOGAR } \\
(\mathrm{t})\end{array}$ & $\begin{array}{l}-0.04 \\
(-2.46)^{* *}\end{array}$ \\
\hline $\begin{array}{c}\text { PIBPO_INI } \\
(\mathrm{t})\end{array}$ & $\begin{array}{l}-0.00002 \\
(-2.46)^{* *}\end{array}$ \\
\hline $\begin{array}{c}\text { D_CAMP } \\
(\mathrm{t})\end{array}$ & $\begin{array}{l}-6.84 \\
(-12.97)^{* * *}\end{array}$ \\
\hline $\mathrm{R}^{2}$ ajustado & 0.53 \\
\hline D. W & 2.01 \\
\hline $\mathrm{F}$ & 16.39 \\
\hline $\begin{array}{l}\text { Jarque Bera } \\
\rho\end{array}$ & $\begin{array}{c}0.04 \\
(0.98)\end{array}$ \\
\hline $\mathrm{NXT}$ & 96 \\
\hline
\end{tabular}

Nota: periodos utilizados: 1993-2000; 2000-2005 y 2005-2010.

Errores estándar corregidos por el método de White, para tratar problemas de heterocedasticidad.

Fuente: estimaciones propias.

* Significativa a $10 \%,{ }^{* *}$ significativa a $5 \%$ y a $1 \%{ }^{* * *}$.

el coeficiente de TCA_IPF ${ }^{9}$ arrojó signos diferentes de acuerdo con la variable dependiente utilizada: positivo para TCA_PO_NOHOGAR y negativo para TCA_POHOGAR. Esto reafirma la idea de que el aumento

${ }^{9}$ Cabe señalar que la variable TCA_IPT que incluye la inversión pública estatal y federal dio resultados similares en términos de signo y valor del coeficiente TCA_IPF, que sólo incluye la federal, pero los estadísticos generales de la regresión salieron más robustos con TCA_IPF. Por otra parte, la variable TCA_IED no resultó estadísticamente significativa. 
en el tamaño de la informalidad y en la economía de subsistencia se asocia con una desaceleración en el crecimiento de la inversión, asimismo que este grupo de actividades se comporta como un residuo entre la oferta de mano de obra y la ocupación en el sector formal, la cual aumenta a medida que se expande la inversión. En cuanto a las variables que capturan el efecto asociado a la disponibilidad de mano de obra educada, sólo PO_EDUC_SUP fue razonablemente significativa y con el signo esperado, con la variable dependiente TCA_POHOGAR (véase figura 13). No obstante, en todos los casos en que dichas variables se incluyeron en la regresión arrojaron los signos esperados: negativo con respecto a TCA_POHOGAR y positivo en relación con TCA_PO_NOHOGAR.

\section{Figura 13}

Función de crecimiento de la ocupación (datos de sección cruzada)

\begin{tabular}{|c|c|c|}
\hline & TCA_POHOGAR & TCA_PO_NOHOGAR \\
\hline C & 3.89 & 2.44 \\
$(\mathrm{t})$ & $(4.45)^{* * *}$ & $(11.15)^{* * *}$ \\
\hline TMN & 1.13 & 1.30 \\
$(\mathrm{t})$ & $(7.23)^{* * *}$ & $(8.78)^{* * *}$ \\
\hline TCA_IPF & -0.12 & 0.05 \\
$(\mathrm{t})$ & $(-3.19)^{* * *}$ & $(1.88)^{*}$ \\
\hline PO_EDUC_SUP & -0.07 & \\
$(\mathrm{t})$ & $(-1.56)$ & 0.66 \\
\hline $\mathrm{R}^{2}$ ajustado & 0.57 & 1.40 \\
\hline D.W & 1.49 & 31.48 \\
\hline F & 14.61 & 0.51 \\
\hline Jarque Bera & 0.20 & $(0.78)$ \\
\hline$\rho$ & $(0.90)$ & 2.81 \\
\hline$\rho$ & 2.07 & $(0.08)$ \\
\hline Breusch-Godfrey (LM) & $(0.16)$ & 1.72 \\
\hline Breusch-Pagan-Godfrey & 2.44 & $(0.20)$ \\
\hline$\rho$ & $(0.09)$ & 32 \\
\hline N & 32 & \\
\hline
\end{tabular}

${ }^{*}$ Significativa a $10 \%,{ }^{* *}$ significativa a $5 \%$ y a $1 \%{ }^{* * *}$.

Fuente: estimaciones propias. 


\section{Discusión de resultados}

Los ejercicios econométricos confirman la importancia de la inversión para explicar diferencias en la TCA_PIB/PO entre entidades federativas, en particular la que realiza el sector público a través de los gobiernos federal y estatal. Desafortunadamente no existe información confiable sobre la inversión privada por estado, excepto la IED, pero tiene el inconveniente de que sus registros toman como referencia la ubicación geográfica de la empresa matriz y no el lugar físico donde se realiza. No obstante, si la inversión pública ejerce un efecto inducción sobre la privada, como suponen algunas teorías, ambas deberían moverse en el mismo sentido y así los cambios porcentuales se aproximarían en el tiempo, y la TCA_IPT/PO sería una buena proxy de la TCA_IT/PO. ${ }^{10}$ Se puede inferir que la lentitud del crecimiento económico nacional responde a un estancamiento de la inversión como sostienen Moreno Brid y Ros (2009), mientras que la agudización de las diferencias interestatales se asocia con su distribución geográfica desigual, sobre todo en el caso de la inversión pública.

Los coeficientes y signos estimados para las variables representativas del capital humano ilustran la importancia tanto de la educación básica como de la superior. ${ }^{11}$ De acuerdo con ello, las diferencias en la dinámica de la productividad laboral están estrechamente asociadas con la capacidad de cada economía para generar demanda por mano de obra educada. En las últimas dos décadas, los indicadores educativos del país han mejorado en forma relevante, por lo que la lentitud del crecimiento no se puede atribuir a un estancamiento en la formación de capital humano. Lo que sí ha ocurrido es una diferenciación entre las entidades, en cuanto a su capacidad para crear puestos laborales que requieren trabajo calificado, situación que ha influido en las trayectorias de sus productos per cápita. Esto está acorde con el signo negativo encontrado en la PO_HOGAR, que captura el efecto asociado con la ocupación en sectores de muy baja productividad, y con el signo positivo obtenido en la variable

\footnotetext{
${ }^{10}$ IT/PO se refiere a la inversión total por persona ocupada.

${ }^{11}$ La variable de educación media superior (PO_EDUC_MSUP) no resultó estadísticamente significativa.
} 
PO_NO_HOGAR, que agrupa al resto de la ocupación. La suma de estos resultados resalta la importancia que tiene el proceso de especialización productiva como motor de desarrollo.

La existencia de una mayor oferta de personal con estudios, profesionistas por ejemplo, es necesaria pero no suficiente para inducir desarrollo, es preciso que haya empleos disponibles que demanden estos recursos, pues de otra manera se ocuparán en actividades ajenas a su formación escolar, y se perderá la oportunidad de incidir favorablemente en el crecimiento económico. Sin embargo, en ausencia de otro tipo de restricciones, como podrían ser la carencia de infraestructura económica o un marco institucional inadecuado, debería haber un círculo virtuoso entre ventajas competitivas basadas en capital humano y atracción de inversiones que usan este tipo de recursos, lo que justificaría cualquier esfuerzo en materia educativa: una disponibilidad elevada de capital humano atrae inversiones que usan de forma intensiva este insumo y, a su vez, al establecerse en la región empresas que demandan personal calificado, se incentiva la inversión social en educación (Easterly 2002).

La migración es otro factor que incide en las trayectorias económicas regionales, cuya influencia es negativa en el desempeño de la productividad laboral, como revela el signo negativo y la alta significancia estadística de la variable TMN. Los estados que atraen mayores flujos migratorios muestran una desaceleración en el incremento del producto por trabajador, y las que expulsan migrantes tienden a mejorar este indicador. La lógica que subyace es que la inmigración aumenta las presiones sobre el mercado de trabajo, y no siempre las economías receptoras tienen la capacidad para absorber esta oferta adicional de mano de obra en empleos de buena calidad; además, este fenómeno propicia que se desvíen recursos públicos que, bajo otras circunstancias, se aplicarían a mejorar las condiciones productivas, para proveer servicios públicos básicos en nuevos asentamientos humanos. La emigración genera los efectos opuestos, pues libera presiones y recursos que mejoran los indicadores de desarrollo. No obstante, la validez de este razonamiento depende de la composición de los flujos migratorios por nivel educativo, pues las economías pueden beneficiarse cuando son receptoras de personal calificado que enriquece sus acervos de capital humano y, por el contrario, verse 
perjudicadas cuando expulsan este tipo de recursos al perder activos valiosos para promover el desarrollo.

Una situación adicional, que parece derivarse de estos ejercicios, es que la localización geográfica importa, y que la apertura comercial ha jugado un papel crucial en la determinación de las diferencias en desempeño económico entre las entidades favoreciendo a las que han sabido aprovechar su cercanía con Estados Unidos, para convertirse en centros exportadores o en receptores de inversión extranjera directa.

En lo que respecta a los ejercicios que explican la dinámica de la ocupación, destaca otra vez la elevada significancia estadística de la TMN, que arroja un signo positivo con respecto a las dos variables dependientes utilizadas: TCA_PO_HOGAR y TCA_PO_NOHOGAR. La migración incide en la ocupación al modificar la PEA, la cual se incrementa en áreas geográficas receptoras y se reduce en las zonas expulsoras. El aumento en la oferta de trabajo favorece una mayor ocupación porque la gente busca actividades para subsistir, pero también porque incide en las ventajas competitivas de la región y, por esa vía, en la asignación de nuevas inversiones. Sin embargo, es posible que una doble causalidad incida en la relación entre la TMN y la TCA PO en la que la TMA determina a la TCA_PO y viceversa, a través de las expectativas optimistas que genera una región, en donde proliferan las oportunidades laborales.

La distribución de puestos de trabajo entre el sector formal e informal de la economía y entre ocupaciones de alta y baja productividad, depende de la magnitud de la inversión y del tipo de industrias o servicios a los que se asignan. Cuando la inversión no crece lo suficiente para absorber el incremento de la PEA, el sector del hogar se expande y con éste las actividades informales y de muy baja productividad; en contraposición, cuando el dinamismo de la inversión permite generar los empleos requeridos, dicho sector tiende a contraerse. Esto puede corroborarse observando los signos negativo y positivo que se obtuvieron para los coeficientes de la TCA_IPF, el primero con respecto a la TCA_POHOGAR y el segundo en relación con la TCA_PO_NOHOGAR. Asimismo, cuando los recursos invertidos se asignan en actividades modernas con uso intensivo de conocimiento, se dinamiza el crecimiento de la productividad, lo que no sucede 
cuando éstas son de corte tradicional, basadas en el uso de recursos naturales o mano de obra barata.

Con respecto al rol de la educación, el cual se mide a través de la disponibilidad de mano de obra con educación básica (PO_EDUC_BAS) O superior (PO_EDUC_SUP), los resultados sugieren que la existencia de un acervo de recursos humanos con alta preparación escolar inhibe el aumento de la ocupación en trabajos de baja productividad, pero no necesariamente lo eleva en los de media y alta. Para que esto último ocurra es indispensable una expansión de la inversión en esos sectores. En otras palabras, un stock de capital humano de alto nivel contribuye a una estructura del empleo más favorable al crecimiento económico, sólo si existen industrias demandantes de este tipo de recursos.

Un resultado que llama la atención en los ejercicios realizados es que la inversión pública proporcionó mejores resultados como variable explicativa que la IED, lo cual podría deberse a problemas de registro de esta última, pero también es probable que la inversión pública tenga un mayor potencial para promover la ocupación y la productividad, sobre todo si se orienta a la provisión de infraestructura y existe un efecto inducción sobre la inversión privada.

\section{Reflexiones finales}

En este trabajo se formuló una explicación sobre las diferencias en tasas de crecimiento entre los estados de México en el periodo 19932010, se destacó la importancia de dos fenómenos que inciden en la trayectoria de la economía nacional y de sus regiones: el cambio demográfico, que modificó la composición por edades de la pirámide poblacional y aceleró el incremento de la PEA con sus consecuentes presiones sobre el mercado laboral, y el lento crecimiento de la inversión, que inhibió la generación de empleos en el sector formal y en ocupaciones de productividad media y alta.

Las disparidades geográficas en la distribución de la inversión y la falta de coincidencia frecuente entre las zonas donde se concentró y las áreas donde aumentó más la oferta de mano de obra alentó la emigración, que se dirigió principalmente hacia Estados Unidos, pero que implicó también un importante flujo interestatal. Como 
resultado de este proceso, las zonas expulsoras de migrantes liberaron presiones que trasfirieron hacia las receptoras, las que en un contexto de inversión insuficiente vieron crecer en forma acelerada la informalidad y los trabajos de subsistencia. Así, los sectores de baja productividad incrementaron su tamaño favoreciendo un patrón de especialización que inhibió el crecimiento económico.

Si bien la expansión de las actividades de baja productividad es un fenómeno nacional, tuvo más incidencia en las entidades donde el aumento de la PEA fue más acelerado, que en muchos casos coinciden con las que registraron tasas más elevadas de migración neta. La mayor disponibilidad de fuerza laboral sin duda ejerció un efecto positivo sobre el PIB, pero lo que ralentizó el crecimiento per cápita de éste fue que buena parte de dicha mano de obra se ocupara en ramos poco productivos y la repercusión que tuvo la migración sobre la dinámica poblacional, toda vez que implicó el cambio de residencia de familias completas. Esto ocurrió por dos vías: una caída en el producto por trabajador y un mayor aumento demográfico.

La disponibilidad de capital humano ejerció un efecto compensador sobre el crecimiento económico, pero sólo en las entidades que lograron atraer inversiones demandantes de trabajo calificado. La existencia de una fuerza laboral más educada redujo la generación de empleos de baja calidad, aunque no la evitó, y de esa manera contribuyó a detener la caída de la productividad laboral en el conjunto de la economía. Esto hace suponer que por lo menos una fracción de las inversiones realizadas en el país durante el periodo decidió su ubicación geográfica tomando en cuenta la accesibilidad a mano de obra educada, además de otros atributos atractivos para las empresas privadas. Sin embargo, los montos invertidos y el ritmo al que se expandieron fueron insuficientes para aprovechar todo el potencial de recursos humanos disponibles a lo largo del país.

De lo anterior se desprende que si bien en el plano nacional fue la atonía de la inversión el factor determinante del lento crecimiento, como lo han afirmado diversos autores, la distribución de éste entre las entidades obedeció a la conjunción de por lo menos tres factores: a) el comportamiento asimétrico de la inversión en cuanto a su asignación geográfica; b) las tendencias demográficas diferenciadas, en particular en lo que se refiere a los flujos migratorios y c) las distintas capacidades para absorber en puestos de trabajo adecuados a la oferta 
disponible de mano de obra educada. La suma de estos factores se tradujo en una variedad de patrones de especialización, con pesos relativos diferenciados de las actividades económicas y, por ende, con distintos niveles y ritmos de crecimiento de la productividad laboral. Estas tendencias, sin duda, fueron condicionadas en mayor o menor medida por la capacidad de cada entidad para insertarse favorablemente en el mercado mundial, la que a su vez estuvo influida por la localización geográfica y por la habilidad de los actores económicos locales para aprovechar sus ventajas naturales.

Los resultados presentados tienen implicaciones importantes para el diseño de las políticas de desarrollo regional; en primer lugar, sugieren la necesidad de cambios en el pacto federal que se traduzcan en apoyos adicionales a los estados, regiones o ciudades receptoras netas de migrantes, y que contribuyen a liberar presiones en los mercados laborales de otras áreas del país, pero que tienen que asumir los costos económicos y sociales asociados con la sobrepoblación y el crecimiento urbano desordenado, como el incremento de la delincuencia y la informalidad, así como la necesidad de proveer servicios públicos por encima de las capacidades financieras de los gobiernos locales. En segundo lugar, evidencian la importancia de adoptar medidas que alienten la redistribución espacial de la inversión para reorientarla hacia las zonas más pobres, una de las cuales podría ser la provisión de infraestructura básica por parte del Estado en las entidades de menor desarrollo, como lo recomiendan Moreno Brid y Ros (2009). Por último, ponen de manifiesto la relevancia de ampliar la cobertura educativa en los distintos niveles escolares, sobre todo en el superior, siempre que ello se acompañe con alguna estrategia para atraer inversiones intensivas en el uso de capital humano.

Recibido en enero de 2014 Aceptado en septiembre de 2014

\section{Bibliografía}

Barro, Robert. 1997. Determinants of economic growth: a cross-country empirical study. Lionel Robbins Lectures. Cambridge: MIT Press. 
Chiquiar, Daniel. 2005. Why Mexico's regional income convergence broke down. Journal of Development Economics 77 (1): 257-275.

De la Fuente, Ángel. 2004. Educación y crecimiento: un panorama. UFAE and IAE working papers 629.04. Instituto de Análisis Económico.

Domar, Evsey. 1946. Capital expansion, rate of growth, and employment. Econometrica 14 (2): 137-147.

Easterly, William. 2002. The elusive quest for growth. Economists' adventures and misadventures in the tropics. Londres: The MIT Press.

Fuentes, Noé y Eduardo Mendoza. 2003. Infraestructura pública y convergencia regional en México, 1980-1998. Comercio Exterior 53 (2): 178-187.

Grosman, Gene y Elhanan Helpman. 1991. Innovation and growth in the global economic. Cambridge: MIT Press.

Harris, John y Michel Todaro. 1970. Migration, unemployment and development: a two sector analysis. American Economic Review 40: 126-42.

Harrod, Roy. 1939. An essay in dynamic theory. The Economic Journal 49 (193): 14-33.

INEGI. 2010. Encuesta nacional de ocupación y empleo. INEGI. 1996. Encuesta nacional de ocupación y empleo. INEGI.

Kaldor, Nicholas. 1970. The case for regional policies. Scottish Journal of Political Economy 17: 337-348.

1966. Causes of the slow growth in the United Kingdom. Cambridge: Cambridge University Press. 
1957. A Model of economic growth. The Economic Journal. 67 (268): 591-624.

Kremer, Michael. 1993. Population growth and technological change: one million B.C. to 1990. Quarterly Journal of Economics 108 (3): 681-716.

Lewis, Arthur. 1954. Economic development with unlimited supplies of labor. Manchester School of Economics and Social Studies 22: 139-191.

Lucas, Robert Jr. 1988. On the mechanics of economic development. Journal of Monetary Economics 22 (1): 3-42.

Mankiw, Gregory, David Romer y David N. Weil. 1992. A contribution to the empirics of economic growth. Quartely Journal of Economics 7 (2): 407-37.

McCombie, John S. L. y Anthony P. Thirlwall. 1994. Economic growth and balance of payments constraint. Nueva York: Palgrave Mcmillan.

Mendoza, Eduardo, Víctor Torres y Mayrén Polanco. 2008. Desigualdad del crecimiento económico regional e innovación tecnológica en México. Comercio Exterior 58 (7): 507-521.

Moreno Brid, Juan Carlos y Jaime Ros. 2009. Development and growth in the Mexican economy. Nueva York: Oxford University Press.

Myrdal, Gunnar. 1957. Economic theory and underdeveloped regions. Londres: Duckworth.

North, Douglas. 1990. Institutions, institutional change and economic performance. Cambridge: Cambridge University Press.

Obregón, Carlos. 2008. Teorías del desarrollo económico. México: Pensamiento Universitario Iberoamericano.

Ocegueda, Juan Manuel. 2000. Crecimiento y desarrollo económico. El estado actual del debate. Mexicali: UABC. 
Ramón Castillo y Rogelio Varela. 2009. Crecimiento regional en México. Especialización y sectores clave. Problemas del Desarrollo (159): 61-84.

Penn World Tables 7.1. 2012. Center for International Comparisons of Production, Income and Prices. University of Pennsylvania: http//pwt.econ.upenn.edu (agosto de 2012).

Rodrik, Dani. 2008. Una economía, muchas recetas. La globalización, las instituciones y el crecimiento económico. México: Fondo de Cultura Económica.

Romer, Paul. 1990. Endogenous technological change. Journal of Political Economy 98: S71-S101.

1986. Increasing returns and long-run growth. The Journal of Political Economy 94 (5): 1002-1037.

Ros, Jaime. 2004. La teoría del desarrollo y la economía del crecimiento. México: Centro de Investigación y Docencia Económicas-Fondo de Cultura Económica.

Rosenstein Rodan, Paul. 1943. Problem of industrialization of eastern and south eastern Europe. Economic Journal 53: 202-211.

Rostow, Walter. 1960. The stages of economic growth: a non-communist manifesto. Cambridge: Cambridge University Press.

Rowthorn, Robert y Ramana Ramaswamy. 1997. Deindustrialization: causes and implications. Working paper 97/42: International Monetary Fund.

Sánchez Juárez, Isaac. L. 2011. Estancamiento económico en México, manufacturas y rendimientos crecientes: un enfoque kaldoriano. Investigación Económica 70 (277): 87-126.

Solow, Robert. 1956. A contribution to the theory of economic growth. The Quarterly Journal of Economics 70 (1): 65-94. 
Thirlwall, Anthony. 1979. The balance of payments constraint as an explanation of international growth rate differences. Banca Nazionale del Lavoro Quarterly Review 128: 45-53.

y Robert Dixon. 1979. A model of export-led growth with balance of payments constraint. En Inflation, development and integration, editado por J. Bowers. Leeds: Leeds University Press.

Yusuf, Shahid y Joseph Stiglitz. 2002. Development issues: settled and open. En Frontiers of development economics. The future in perspective, editado por Gerald M. Meier y Joseph Stiglitz, 227-268. Washington: World Bank-Oxford University Press. 